\title{
Globus Pallidus Neurons Dynamically Regulate the Activity Pattern of Subthalamic Nucleus Neurons through the Frequency-Dependent Activation of Postsynaptic GABA and $\mathrm{GABA}_{\mathrm{B}}$ Receptors
}

\author{
Nicholas E. Hallworth and Mark D. Bevan \\ Department of Physiology, Feinberg School of Medicine, Northwestern University, Chicago, Illinois 60611-3008
}

\begin{abstract}
Reciprocally connected GABAergic neurons of the globus pallidus (GP) and glutamatergic neurons of the subthalamic nucleus (STN) are a putative generator of pathological rhythmic burst firing in Parkinson's disease (PD). Burst firing of STN neurons may be driven by rebound depolarization after barrages of $\mathrm{GABA}_{\mathrm{A}}$ receptor $\left(\mathrm{GABA}_{\mathrm{A}} \mathrm{R}\right)$-mediated IPSPs arising from pallidal fibers. To determine the conditions under which pallidosubthalamic transmission activates these and other postsynaptic GABARs, a parasagittal mouse brain slice preparation was developed in which pallidosubthalamic connections were preserved. Intact connectivity was first confirmed through the injection of a neuronal tracer into the GP. Voltage-clamp and gramicidin-based perforated-patch current-clamp recordings were then used to study the relative influences of $\mathrm{GABA}_{\mathrm{A}} \mathrm{R}$ - and $\mathrm{GABA}_{\mathrm{B}} \mathrm{R}$-mediated pallidosubthalamic transmission on STN neurons. Spontaneous phasic, but not tonic, activation of postsynaptic $\mathrm{GABA}_{\mathrm{A}} \mathrm{Rs}$ reduced the frequency and disrupted the rhythmicity of autonomous firing in STN neurons. However, postsynaptic $\mathrm{GABA}_{\mathrm{B}}$ Rs were only sufficiently activated to impact STN firing when pallidosubthalamic transmission was elevated or pallidal fibers were synchronously activated by electrical stimulation. In a subset of neurons, rebound burst depolarizations followed high-frequency, synchronous stimulation of pallidosubthalamic fibers. Although $\mathrm{GABA}_{B} \mathrm{R}-$ mediated hyperpolarization was itself sufficient to generate rebound bursts, coincident activation of postsynaptic $\mathrm{GABA}_{\mathrm{A}} \mathrm{Rs}$ produced longer and more intense burst firing. These findings elucidate a novel route through which burst activity can be generated in the STN, and suggest that GABARs on STN neurons could act in a synergistic manner to generate abnormal burst activity in PD.
\end{abstract}

Key words: basal ganglia; network; synchrony; burst; synaptic transmission; Parkinson’s disease

\section{Introduction}

The frequency and pattern of action potentials generated by neurons within the subthalamic nucleus (STN) are important determinants of both the normal and pathological output of the basal ganglia. In resting animals, STN neurons are spontaneously active, with a firing rate between 10 and $30 \mathrm{~Hz}$ and an irregular firing pattern (Wichmann et al., 1994; Urbain et al., 2002). During movement, STN neurons display somatotopic, spatiotemporally related changes in activity. In parkinsonian animals, in which movement is impaired, precise somatotopy is lost, and there is an emergence of correlated, rhythmic burst firing (Bergman et al., 1994; Soares et al., 2004). Such activity, which is phaserelated to resting tremor, is also a feature of STN recordings from Parkinson's disease (PD) patients (Hutchison et al., 1998; Levy et al., 2000; Amirnovin et al., 2004).

Received Feb. 2, 2005; revised April 12, 2005; accepted May 19, 2005.

This work was supported by National Institute of Neurological Disorders and Stroke Grants NS041280 (M.D.B.) and NS047085 (M.D.B.). We thank Drs. Hitoshi Kita, James Surmeier, and Charles Wilson for helpful discussions throughout this study.

Correspondence should be addressed to Dr. Mark D. Bevan, Department of Physiology, Feinberg School of Medicine, Northwestern University, 303 East Chicago Avenue, Chicago, IL 60611-3008. E-mail:m-bevan@northwestern.edu. DOl:10.1523/JNEUROSC1.0450-05.2005

Copyright $\odot 2005$ Society for Neuroscience $\quad$ 0270-6474/05/256304-12\$15.00/0
STN burst firing may be driven, in part, by reciprocally connected GABAergic neurons of the globus pallidus (GP) (Plenz and Kital, 1999; Gillies et al., 2002; Terman et al., 2002). In vitro, stimulation of barrages of phasic $\mathrm{GABA}_{\mathrm{A}}$ IPSPs can sufficiently hyperpolarize STN neurons so that on termination of synaptic activity there is a rebound depolarization, which may be associated with a burst of high-frequency firing (Bevan et al., 2002a). This rebound burst activity may be generated in STN neurons in vivo if GABAergic inputs from the GP are correlated, as in idiopathic and experimental models of PD (Raz et al., 2000; Levy et al., 2002; Soares et al., 2004).

GABA released from pallidosubthalamic terminals may also bind other pathophysiologically relevant postsynaptic targets. In the hippocampus and cerebellum, extrasynaptic $\mathrm{GABA}_{\mathrm{A}}$ receptors $\left(\mathrm{GABA}_{\mathrm{A}} \mathrm{Rs}\right)$ mediate a tonic current that profoundly influences postsynaptic excitability (Brickley et al., 1996; Semyanov et al., 2004). Although extrasynaptic $\mathrm{GABA}_{\mathrm{A}} \mathrm{Rs}$ have been identified on STN neurons (Galvan et al., 2004), tonic current has not been studied. In addition, STN neurons express relatively high levels of $\mathrm{GABA}_{\mathrm{B}} \mathrm{Rs}$, primarily at extrasynaptic sites (Galvan et al., 2004). Although $\mathrm{GABA}_{\mathrm{B}} \mathrm{Rs}$ are activated by the direct application of agonists, $\mathrm{GABA}_{\mathrm{B}} \mathrm{R}$ antagonists have no impact on STN firing dynamics (Shen and Johnson, 2001; Urbain et al., 2002; Wilson et 
al., 2004). As such, it is unclear under what conditions postsynaptic $\mathrm{GABA}_{\mathrm{B}} \mathrm{Rs}$ are activated by pallidal input. At other synapses, the activation of extrasynaptic $\mathrm{GABA}_{\mathrm{B}}$ Rs requires an elevated concentration of extracellular GABA (Mody et al., 1994; Isaacson, 2000), which arises during synchronous presynaptic activity, for example, during hippocampal or thalamic oscillations (Kim et al., 1997; Scanziani, 2000; Jacobsen et al., 2001). In these regions, activation of postsynaptic $\mathrm{GABA}_{\mathrm{B}} \mathrm{Rs}$ modulates the frequency of the network rhythm. It appears then, that the synchronous firing of GP neurons, characteristic of PD, could lead to the activation of STN GABA $\mathrm{B}_{\mathrm{B}}$ Rs. Given that the impact of extrasynaptic $G_{A B A} R$ and $G_{A B A} R$ activation may be as significant as that of synaptic $\mathrm{GABA}_{\mathrm{A}} \mathrm{R}$ activation, we developed a brain slice preparation, in which STN neurons received spontaneous GABAergic input from the GP, to study the relative contributions of postsynaptic GABAR activation on STN activity.

\section{Materials and Methods}

Slice preparation. Experimental procedures were performed using brain slices obtained from 62 13- to 21-d-old male C57BL/6 mice. All experiments were conducted in compliance with the rules set forth by the Northwestern University Animal Care and Use Committee and the National Institutes of Health Guide for the Care and Use of Laboratory Animals. Animals were deeply anesthetized with ketamine-xylazine and perfused transcardially with $10 \mathrm{ml}$ of ice-cold modified artificial CSF (ACSF), which had been bubbled with $95 \% \mathrm{O}_{2}$ and $5 \% \mathrm{CO}_{2}$ and contained the following (in mM): 230 sucrose, $2.5 \mathrm{KCl}, 26 \mathrm{NaHCO}_{3}, 1.25$ $\mathrm{NaH}_{2} \mathrm{PO}_{4}, 0.5 \mathrm{CaCl}_{2}, 10 \mathrm{MgSO}_{4}$, and 10 glucose. After perfusion, the animal was decapitated, and the brain was rapidly removed from the skull. In an attempt to maintain the pallidosubthalamic projection, 350$\mu \mathrm{m}$-thick parasagittal slices were cut at an angle of $20^{\circ}$ from the midline, measured from the caudal pole of the brain. To do this, each hemisphere of the brain was glued, medial face down, to a $20^{\circ}$ Perspex ramp, fixed to the stage of a vibratome (Vibratome 3000; Vibratome, St. Louis, MO), and then immersed in ice-cold modified ACSF. In this manner, one or two slices that contained both STN and GP were obtained from each hemisphere. For experiments in which slices were bathed in 4-aminopyridine (4-AP), a small razor cut was made caudal to the GP to sever GP axons from their parent cell bodies, so that there was no confounding influence of this agent on the somatodendritic excitability of GP neurons. Slices were subsequently transferred to a holding chamber, where they were submerged in ACSF, which was bubbled continuously with $95 \% \mathrm{O}_{2}$ and $5 \% \mathrm{CO}_{2}$, maintained at room temperature, and contained the following (in $\mathrm{mm}$ ): $126 \mathrm{NaCl}, 2.5 \mathrm{KCl}, 26 \mathrm{NaHCO}_{3}, 1.25$ $\mathrm{NaH}_{2} \mathrm{PO}_{4}, 2 \mathrm{CaCl}_{2}, 2 \mathrm{MgSO}_{4}$, and 10 glucose

Visualized recording. Single slices were transferred to a submerged recording chamber and continuously perfused $(2-3 \mathrm{ml} / \mathrm{min}$ ) with a slightly modified oxygenated ACSF that contained the following (in mM): 126 $\mathrm{NaCl}, 3.5 \mathrm{KCl}, 26 \mathrm{NaHCO}_{3}, 1.25 \mathrm{NaH}_{2} \mathrm{PO}_{4}, 1 \mathrm{CaCl}_{2}, 1 \mathrm{MgCl}_{2}$, and 10 glucose. This solution is believed to more accurately represent the ionic composition of brain interstitial fluid than traditional ACSF (SanchezVives and McCormick, 2000). Except for recordings addressing tonic current, for which the bath solution was kept at room temperature to maintain long-term baseline stability (Brickley et al., 1996; Semyanov et al., 2003; Yeung et al., 2003), all recordings were made with the bath solution heated to between 35 and $37^{\circ} \mathrm{C}$. A $40 \times$ water immersion objective was used to identify individual cells within the STN using infragradient contrast video microscopy (Infrapatch Workstation; Luigs and Neumann, Ratingen, Germany). Somatic recordings were made using patch pipettes pulled from nonfilamented borosilicate glass (Warner Instrument, Hamden, CT) on a P-97 Flaming/Brown micropipette puller (Sutter Instrument, Novato, CA). For voltage-clamp recordings, pipettes were filled with a solution containing the following (in $\mathrm{mm}$ ): $135 \mathrm{CsCl}$, 3.6 $\mathrm{NaCl}, 1 \mathrm{MgCl}_{2}, 10$ HEPES, $0.1 \mathrm{Na}_{4}$ EGTA, $0.4 \mathrm{Na}_{3} \mathrm{GTP}$, and $2 \mathrm{Mg}_{1.5}$ ATP. $\mathrm{N}$-2(2,6-Dimethylphenylcarbamoylmethyl)triethylammonium bromide (QX314) (2.5 mM) was also included in the majority of pipettes used for voltage-clamp recordings to block postsynaptic sodium, potassium, and hyperpolarization-activated cation currents. For current-clamp recordings, pipettes were filled with a solution containing the following (in mM): $110 \mathrm{~K}-\mathrm{MeSO}_{4}, 25 \mathrm{KCl}, 3.6 \mathrm{NaCl}, 1 \mathrm{MgCl}_{2}$ 10 HEPES, $0.1 \mathrm{Na}_{4}$ EGTA, $0.4 \mathrm{Na}_{3} \mathrm{GTP}$, and $2 \mathrm{Mg}_{1.5}$ ATP. All internal solutions were made up to a $\mathrm{pH}$ of 7.3 and an osmolarity of $\sim 290 \mathrm{Osm}$. For current-clamp recordings, moments before seal formation was attempted, gramicidin was added to the pipette solution at a concentration of $\sim 20 \mu \mathrm{g} / \mathrm{ml}$. Cell-attached patch recordings were made with pipettes filled with the same solution as that used in the bath. The resistance of filled pipettes was between 2 and $6 \mathrm{M} \Omega$. Membrane activity was directly recorded after seal formation in the voltage-clamp mode at a holding potential of $0 \mathrm{mV}$ for cell-attached experiments, after adequate perforation (with a series resistance between 30 and $70 \mathrm{M} \Omega$ ) in current-clamp mode, and after seal rupture (whole-cell configuration) in the voltageclamp mode using an EPC 9/2.C amplifier (HEKA Elektronik, Lambrecht, Germany), which was operated using Pulse 8.5 software (HEKA Elektronik). Signals were low-pass filtered at a frequency $(1.7-17 \mathrm{kHz})$ that was one-third of the frequency of digitization $(5-50 \mathrm{kHz})$. All current-clamp data and the majority of voltage-clamp data were sampled at $50 \mathrm{kHz}$. Very long periods ( $>5 \mathrm{~min}$ ) of voltage-clamp data were sampled at lower frequencies to maintain manageable file sizes. Deliberate or accidental establishment of the whole-cell configuration from the perforated configuration was recognized as a sudden drop in series resistance, an increase in the amplitude of recorded action potentials, a depolarizing

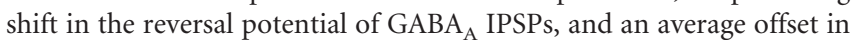
membrane potential of $5.2 \mathrm{mV}$. The value of the offset was similar to the empirically calculated (Barry, 1994) junction potential between the electrode solution and the external media of $8.1 \mathrm{mV}$. Thus, the voltage reported for perforated patch current-clamp data in this study is therefore likely to be $<3 \mathrm{mV}$ more depolarized than the true voltage. The empirically calculated junction potential between the bath solution and the intracellular solution used for voltage-clamp experiments was found to be $5 \mathrm{mV}$; this potential has been applied to all relevant command potentials. Whereas fast capacitive transients of the pipette were nulled on-line, there was no compensation of series resistance or whole-cell capacitance. For voltage-clamp recordings, series resistance was measured from the membrane response to a 50 -ms-long, $10 \mathrm{mV}$ hyperpolarizing step from the holding potential. Voltage-clamp recordings with series resistances that fluctuated $>20 \%$ within an experiment were not included in the analyses. For current-clamp data, the deviation in voltage response attributable to series resistance was subtracted off-line as described previously (Bevan et al., 2000).

In a subset of current-clamp experiments, an attempt was made to evoke IPSPs in individually recorded STN neurons through bipolar electrical stimulation of the GP or internal capsule. The poles of stimulation were selected from a custom-built matrix of four rows of five electrodes (FHC, Bowdoinham, ME). Electrodes within a row were $240 \mu \mathrm{m}$ apart, and rows were offset by $600 \mu \mathrm{m}$. The two electrodes selected for stimulation were those that produced the largest IPSP in the absence of antidromic activation. Typically, stimulus intensity was $200-400 \mu \mathrm{A}$. A single pulse of stimulation was $100 \mu$ s long.

Reagents. Drugs were prepared as concentrated stock solutions and diluted in ACSF, before being, in most cases, bath applied. For the analysis of tonic current, $\mathrm{GABA}_{\mathrm{A}} \mathrm{R}$ antagonists were fast-applied directly to the STN using a gravity-driven sewer pipe perfusion system (Cell MicroControls, Norfolk, VA). Ionotropic glutamatergic transmission was blocked by the continuous application of $50 \mu \mathrm{M}$ D-(-)-2-amino-5phosphonopentanoic acid (APV) and $20 \mu \mathrm{M}$ 6,7-dinitroquinoxaline-2,3dione (DNQX). These agents, plus SR 95531 [2-(3-carboxypropyl)-3amino-6-(4-methoxyphenyl)pyridazinium] hydrobromide [gabazine (GBZ)], (2S)-3-[[(1S)-1-(3,4-dichlorophenyl)ethyl] amino-2-hydroxypropyl] (phenylmethyl)phosphinic acid (CGP), QX314, and picrotoxin were obtained from Tocris (Ellisville, MO). Gramicidin, biocytin, and 4-AP were obtained from Sigma (St. Louis, MO).

Data analysis. The frequency of occurrence of synaptic events, as well as their peak amplitude, $10-90 \%$ rise time, area, and weighted decay were obtained using pClamp (Molecular Devices, Union City, CA). The total net inward charge was calculated by integrating all periods in which current was $>2$ SDs below the mean baseline holding current. Thus, 
mean charge $(\mathrm{pC} / \mathrm{s})$ represents the total charge, calculated in this manner, divided by the length of the period analyzed. The mean baseline holding current was calculated using 20-50 100-mslong segments during which no IPSCs were evident.

The time of the positive peak of single action potentials/currents recorded in current-clamp/ cell-attached mode was obtained using Origin 5.0 (Microcal Software, Northampton, MA) and used to calculate the mean interspike interval (ISI). The precision of single-spike activity was quantified using the coefficient of variation $(\mathrm{CV})$, which was obtained for a period of data (typically the first 101 events within a recorded sequence of activity) by dividing the SD of ISIs by the mean ISI.

Numerical data are presented as mean $\pm \mathrm{SD}$, and the distribution of data is represented graphically in box plots. In these, the central line represents the median, the inner edges represent the interquartile range, and the outer edges represent the $1-99 \%$ range. The mean of the data is also represented with a filled square. Although data sets did not appear to deviate from a normal distribution, sample sizes were small. Therefore, nonparametric statistics were used because they are subject to fewer assumptions concerning the distribution of data. Paired and unpaired experimental data sets were compared using the Wilcoxon signed rank (WSR) test and the Mann-Whitney $U$ (MWU) test, respectively, and values of $p<0.05$ were considered significant. The Kolmogorov-Smirnov $(\mathrm{K}-\mathrm{S})$ test was used to compare the frequency distributions of the firing rate and $\mathrm{CV}$ of GP neurons with normal distributions of random numbers with similar means and SDs, generated using Statview (SAS Institute, Cary, NC). Statistical analyses were also performed using JMP (SAS Institute).

Histology. Injections of biocytin (3\%, dissolved in ACSF) were made at two to three sites $(10-150 \mu \mathrm{l} /$ site $)$ within the GP of parasagittal slices held in an interface chamber (Fine Science Tools, Foster City, CA), using a $1.0 \mu \mathrm{l}$ (26 gauge) syringe that was connected to a glass micropipette to minimize disruption at the injection site. Injections were made over 5-20 min at each site. The syringe was retracted $\sim 5 \mathrm{~min}$ after each injection. Slices were then held in the chamber for $5-7 \mathrm{~h}$ before overnight fixation at $4^{\circ} \mathrm{C}$ in $4 \%$ paraformaldehyde diluted in $0.1 \mathrm{M}$ phosphate buffer, pH 7.4 (PB). Slices were then washed in PBS before incubation, for $4-6 \mathrm{~h}$ at room temperature, in avidin-biotin-peroxidase complex (Vectastain Elite ABC; Vector Laboratories, Burlingame, CA) diluted (1:50) in PBS containing 1\% bovine serum albumin and $0.3 \%$ Triton X-100. Avidin-biotin-peroxidase bound to biocytin tracer was then visualized using diaminobenzidine tetrahydrochloride (DAB peroxidase kit; Vector Laboratories). After the reaction, slices were washed in $0.1 \mathrm{M} \mathrm{PB}$ and treated with $\mathrm{OsO}_{4}(0.2 \%$ in $0.1 \mathrm{M} \mathrm{PB})$ for $20-30$ $\mathrm{min}$. Slices were then dehydrated in a graded series of alcohol and propylene oxide before being embedded in Durcupan resin (Fluka, Seelze, Germany) on glass slides. The resin was then cured for $24 \mathrm{~h}$ at $60^{\circ} \mathrm{C}$. Analysis and digital micrography of biocytin-labeled neuronal elements were performed using a Zeiss (Thornwood, NY) Axioskop microscope equipped with a digital CCD camera (Axiocam; Zeiss) that was operated using Axiovision software (Zeiss).
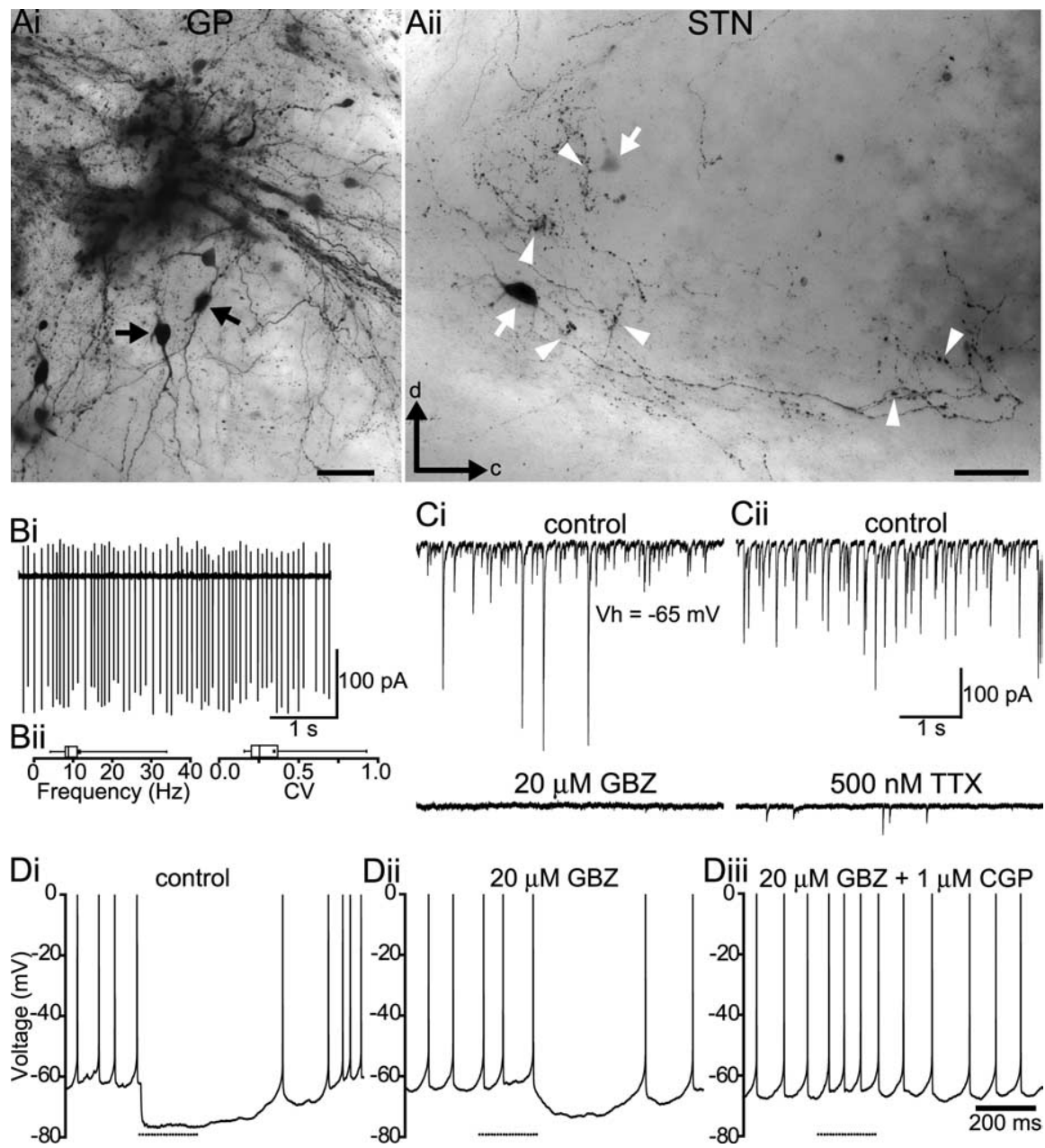

Figure 1. Evidence for intact pallidosubthalamic projections in parasagittal slices. Ai, Aii, Photomicrographs of a site of limited biocytin injection in the GP (Ai) and corresponding labeling in the STN of the same slice (Aii). Ai, Extracellular deposits of tracer were taken up by neurons within the GP (black arrows). Aii, Labeled fibers were seen in the STN. Some axons possessed multiple varicosities that appeared to contact the proximal regions of unlabeled STN neurons (white arrowheads). Retrogradely labeled in the parasagittal preparation. $\boldsymbol{B i}$, Representative cell-attached recording from a GP neuron within a slice bathed in APV and transient inward currents are seen in a voltage-clamp recording of an STN neuron held at $-65 \mathrm{mV}$ and bathed in APV an ring transient inward currents were also reduced in frequency and mean charge by bath application of TTX. Di-Diii, Stimulation-

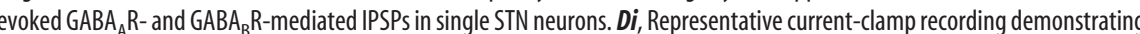
STN neurons within parasagittal slices. In this and subsequent figures, action potentials have been truncated at $0 \mathrm{mV}$ and stimulus component of the hyperpolarizing response was sensitive to the application of $20 \mu \mathrm{MGBZ}$, a major portion of this response remained under these conditions. Diii, The second component of the response was removed by the application of $1 \mu \mathrm{M}$ CGP.

\section{Results}

\section{Anatomical and functional connectivity is maintained in the} parasagittal preparation

To determine whether pallidosubthalamic projections were maintained in our preparation, we performed extracellular injections of biocytin in the GP of eight parasagittal slices. Analysis of each slice confirmed that biocytin was injected solely $(n=4)$ or predominantly $(n=4)$ into the GP (Fig. $1 A i)$. Both anterogradely labeled axons/terminals and retrogradely labeled neurons were observed in the STN in six of eight slices (Fig. 1Aii). The appearance of many of the labeled axons and their termination pattern were similar to those described previously in studies of 
labeled GP neurons: individual axons possessed several large varicosities, which apposed the soma and proximal regions of STN neurons (Bevan et al., 1997, 1998).

To ascertain the level of activity of GP neurons, cell-attached patch recordings were obtained from parasagittal slices bathed in $50 \mu \mathrm{M}$ APV and $20 \mu \mathrm{M}$ DNQX. Membrane seals always led to electrode-tip resistances that were $>300 \mathrm{M} \Omega$, and data were accepted only if the signal-to-noise ratio was $>4$. Although reasonable membrane-patch seals were obtained in 16 cases, four putative neurons remained silent throughout the recording period. As can be seen in Figure 1, Bi and Bii, the remaining 12 neurons were spontaneously active, firing in a single-spike manner with an average firing rate of $11.4 \pm 7.6 \mathrm{~Hz}$, which is within the range previously reported for spontaneously active GP neurons in mouse (Chan et al., 2004), rat (Cooper and Stanford, 2000), and guinea pig slice preparations (Nambu and Llinas, 1994), but well below the $25-100 \mathrm{~Hz}$ typically recorded from the GP in alert, resting rodents and primates (DeLong, 1971; Gardiner and Kitai, 1992; Raz et al., 2000; Urbain et al., 2000; Kita et al., 2004; Soares et al., 2004). Single-spike firing was irregular: the average CV across the 12 neurons was $0.35 \pm 0.22$ (Fig. 1 Bii). Neither the frequency distribution of mean firing rate $(n=12 ; \mathrm{K}-\mathrm{S}$ test; $p=$ $0.9447)$ or mean CV $(n=12 ; \mathrm{K}-\mathrm{S}$ test; $p=0.5272)$ were significantly different from a normal distribution, suggesting that the data were derived from a single population of neurons with respect to their spontaneous firing activity.

To assess whether these spontaneously active GP neurons provided a $\mathrm{GABA}_{\mathrm{A}} \mathrm{R}$-mediated input to the STN, whole-cell recordings were performed using cesium chloride-containing pipettes, and STN neurons were voltage-clamped at a holding potential of $-65 \mathrm{mV}$. As seen in Figure 1, Ci and Cii, spontaneous, irregular, transient inward currents were recorded from STN neurons under control conditions (slices bathed in $50 \mu \mathrm{M}$ APV and $20 \mu \mathrm{M}$ DNQX). The average spontaneous event recorded from 19 neurons under these conditions had an amplitude of $-64.0 \pm 25.7$ $\mathrm{pA}$, a $10-90 \%$ rise time of $0.84 \pm 0.26 \mathrm{~ms}$, and a weighted decay time constant of $8.4 \pm 3.2 \mathrm{~ms}$. The kinetics of the events recorded in the parasagittal slice are comparable with those measured for spontaneous events recorded from STN neurons within rat coronal slices (Baufreton et al., 2001) (reported decay, $\sim 10 \mathrm{~ms}$ ). The spontaneous events recorded from all 19 STN cells in the parasagittal slice occurred with a mean frequency of $15.5 \pm 14.7 \mathrm{~Hz}$ and carried a mean charge of $6.9 \pm 7.4 \mathrm{pC} / \mathrm{s}$. The $\mathrm{GABA}_{\mathrm{A}} \mathrm{R}$ antagonists $\operatorname{GBZ}(20 \mu \mathrm{M} ; n=3)$ or picrotoxin $(100 \mu \mathrm{M} ; n=7)$ were bath applied after the acquisition of sufficient control data for 10 of these neurons, in which events occurred with a mean frequency of $11.0 \pm 7.8 \mathrm{~Hz}$ and carried a mean charge of $4.0 \pm 2.4$ pC/s (Fig. $1 \mathrm{Ci}$ ). In all 10 recordings, application of the antagonists significantly reduced both the frequency and size of these events (WSR tests; $\mathrm{GABA}_{\mathrm{A}}$-blocked frequency, $0.7 \pm 0.8 \mathrm{~Hz} ; n=$ $10 ; p=0.002 ; \mathrm{GABA}_{\mathrm{A}}$-blocked mean charge, $0.2 \pm 0.1 \mathrm{pC} / \mathrm{s} ; n=$ $10 ; p=0.002)$. The nine other neurons were challenged with 500 nM TTX (Fig. 1Cii). The mean frequency of events recorded under these conditions was one-half of that recorded under control conditions (WSR test; control, $20.5 \pm 19.1 \mathrm{~Hz}$; TTX, $10.9 \pm 9.2$ $\mathrm{Hz} ; n=9 ; p=0.004)$. Bath-applied TTX also significantly reduced the mean charge of spontaneously occurring events (WSR test; control, $10.0 \pm 9.8 \mathrm{pC} / \mathrm{s}$; TTX, $3.4 \pm 3.2 \mathrm{pC} / \mathrm{s} ; n=9 ; p=$ $0.02)$. Thus, phasic currents recorded from STN neurons in the parasagittal preparation are reduced by $\mathrm{GABA}_{\mathrm{A}}$ antagonists and voltage-dependent sodium $\left(\mathrm{Na}_{\mathrm{V}}\right)$ channel blockade. Because the cell-attached recordings from GP neurons and voltage-clamp recordings from STN neurons determined the firing rate of GP neurons and the frequency of spontaneous postsynaptic events, respectively, it is tempting to make inferences concerning the pattern of innervation of STN neurons by GP neurons. However, this was not attempted given that the probability of release of GABA from GP terminals is unknown and the number of GPSTN axons retained within the slice underrepresents the number in the intact brain.

To provide additional evidence that the transient inward currents observed in our voltage-clamp recordings represent GABAergic transmission at pallidosubthalamic synapses, bipolar electrical stimulation was applied to the GP in parasagittal slices bathed in $50 \mu \mathrm{M}$ APV and $20 \mu \mathrm{M}$ DNQX. IPSPs evoked in the STN were recorded using the gramicidin-based perforated-patch current-clamp technique. In 10 of 10 neurons in which recordings were obtained, single pulses of bipolar stimulation applied to the GP elicited single IPSPs (data not shown). These IPSPs ranged in size from 5 to $15 \mathrm{mV}$, and had similar kinetics to those observed by Bevan et al. (2002a). By evoking IPSPs at various levels of polarization in six of these cells, it was determined that the equilibrium potential of $\mathrm{GABA}_{\mathrm{A}}$ IPSPs was $-78.9 \pm 2.5 \mathrm{mV}$. In all 10 neurons examined, a single pulse of bipolar stimulation could no longer elicit any postsynaptic response after the bath

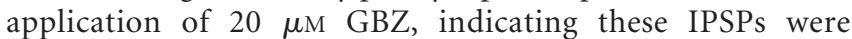
$\mathrm{GABA}_{\mathrm{A}} \mathrm{R}$ mediated. Paired with the anatomical evidence, the data obtained from these recordings suggest that the most likely source of spontaneous GABAergic input to the STN in parasagittal slices is the GP.

Trains of bipolar stimulation were also applied to the GP while the membrane potential of single STN neurons was monitored with current-clamp recordings. Barrages of summating IPSPs coincident with the stimulating train were evident in recordings from the same group of 10 neurons described above, in response to sequences of 20 pulses delivered to the GP at $100 \mathrm{~Hz}$ (Fig. 1 Di). These IPSPs were blocked with $20 \mu \mathrm{M} \mathrm{GBZ}$ in 10 of 10 neurons. In two other neurons, a profound and prolonged hyperpolarization persisted after this treatment (Fig. 1 Dii). This hyperpolarization was subsequently blocked by the application of $1 \mu \mathrm{M}$ CGP (Fig. 1 Diii). Thus, both $\mathrm{GABA}_{\mathrm{A}} \mathrm{R}$ - and $\mathrm{GABA}_{\mathrm{B}} \mathrm{R}$-mediated responses can be observed in individual STN neurons after stimulation of the GP.

\section{STN firing dynamics are shaped by spontaneous $\mathrm{GABA}_{\mathrm{A}} \mathrm{R}$ - but not $\mathrm{GAB} \mathrm{A}_{\mathrm{B}} \mathrm{R}$-mediated input}

The data obtained from whole-cell voltage-clamp recordings suggest that, in the parasagittal preparation, the neurons of the STN are subject to a consistent level of spontaneously occurring $\mathrm{GABA}_{\mathrm{A}} \mathrm{R}$-mediated input. To examine the effect of this input on firing dynamics, gramicidin-based perforated-patch current clamp recordings were obtained from 22 STN neurons, bathed in $50 \mu \mathrm{M}$ APV and $20 \mu \mathrm{M}$ DNQX. Previous perforated-patch recordings have suggested that, in the absence of synaptic input, the neurons of the STN fire in a regular, single-spike manner (Bevan et al., 2002a; Hallworth et al., 2003). STN neurons in parasagittal slices also fired in a single-spike manner, with a mean firing rate of $9.6 \pm 7.5 \mathrm{~Hz}(n=22)$, but as seen in Figure $2 A$, firing was irregular, producing an average CV of $0.30 \pm 0.29$. In most cells, ongoing barrages of IPSPs were readily apparent. Application of GBZ $(20 \mu \mathrm{M})$ led to a significant increase in the average firing rate of these cells (WSR test; GBZ frequency, $11.7 \pm 7.7 \mathrm{~Hz} ; n=22$; $p=0.005$ ) (Fig. $2 B, C$ ). The antagonist also led to a significant decrease in the average CV (WSR test; GBZ CV, $0.17 \pm 0.09 ; n=$ $22 ; p=0.004$ ) (Fig. $2 B, C$ ), as the occurrence of action potentials shifted to a more regular, precise pattern. 
A

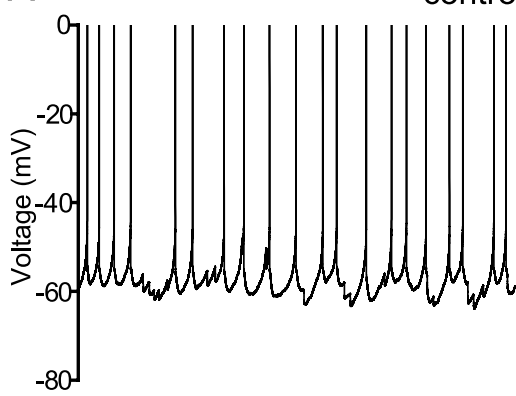

control

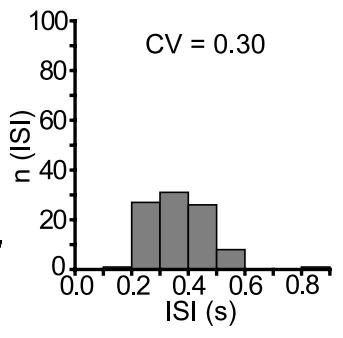

$\mathrm{B}$

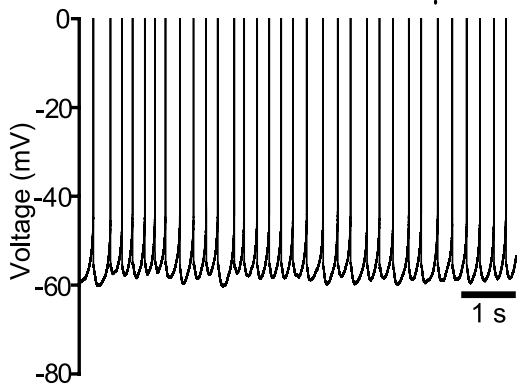

$20 \mu \mathrm{M} \mathrm{GBZ}$

$\mathrm{C}_{35}$
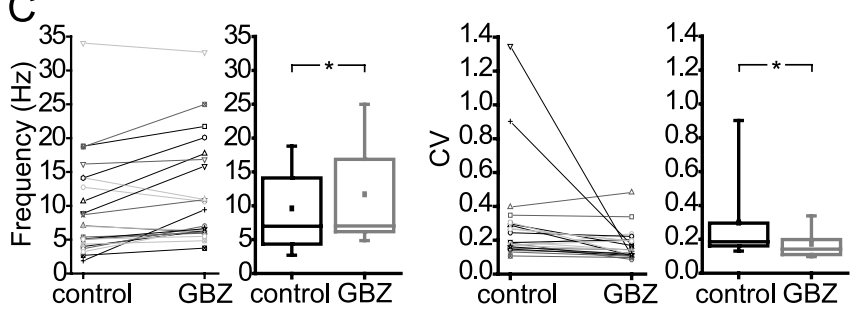

Figure 2. Spontaneous $G A B A_{A} R$-mediated IPSPs disrupt the pace and precision of firing of STN neurons. $\boldsymbol{A}, \boldsymbol{B}$, Activity of a representative neuron under control conditions and after bath application of GBZ. The ISI histograms generated from $100 \mathrm{ISI}$ occurring during the respective conditions for this neuron are shown to the right. $A$, Single-spike firing was slow and irregular before drug application, and IPSPs were evident during the ISIs (frequency, $2.7 \mathrm{~Hz} ; \mathrm{CV}, 0.30) . \boldsymbol{B}$, Blockade of $\mathrm{GABA}_{A} \mathrm{Rs}$ with $20 \mu \mathrm{M} \mathrm{GBZ}$ increased the frequency and precision of activity (frequency, $3.7 \mathrm{~Hz} ; \mathrm{CV}, 0.17)$. C, Population firing rate and $\mathrm{CV}$ data. Nonparametric paired comparisons revealed that the mean firing rate in control was significantly lower than the mean firing rate in GBZ and that the mean $C V$ in control was significantly higher than the mean CV in GBZ. ${ }^{*} p<0.05$. Calibration in $\boldsymbol{B}$ also applies to $\boldsymbol{A}$.

GABAergic input from the GP may also influence STN firing rate and pattern through the activation of postsynaptic GAB$\mathrm{A}_{\mathrm{B}}$ Rs. To test this hypothesis, current-clamp recordings were obtained from 10 STN neurons in parasagittal slices in which fast glutamatergic and GABAergic synaptic transmission was blocked. Under these conditions, STN neurons fired in a regular, single-spike manner $(\mathrm{CV}, 0.16 \pm 0.04)$ with a frequency of $9.8 \pm$ $5.6 \mathrm{~Hz}$ (data not shown). The pace and precision of firing was not significantly changed by the subsequent application of $1 \mu \mathrm{M}$ CGP, a selective $\mathrm{GABA}_{\mathrm{B}}$ antagonist (WSR tests; CGP frequency, $11.6 \pm$ $5.4 \mathrm{~Hz} ; n=10 ; p=0.064$; CGP CV, $0.14 \pm 0.03 ; n=10 ; p=$ $0.16)$, suggesting that GABA released spontaneously in parasagittal slices does not sufficiently activate postsynaptic $G_{A B A}$ Rs to influence STN activity.

\section{Postsynaptic $\mathrm{GABA}_{\mathrm{A}} \mathrm{Rs}$ are not tonically active}

Tonic current is thought to be mediated by $\mathrm{GABA}_{\mathrm{A}}$ Rs primarily located at extrasynaptic sites, but different receptor subtypes are involved in specific neuronal populations (Mody, 2001; Stell et al., 2003; Caraiscos et al., 2004; Semyanov et al., 2004). A significant proportion of $\alpha_{1}$ subunit-containing $\mathrm{GABA}_{\mathrm{A}}$ Rs expressed on STN neurons are extrasynaptic (Galvan et al., 2004), and in situ hybridization has demonstrated that STN neurons express mRNA for $\gamma$ and $\delta$ subunits (Wisden et al., 1992; Fritschy and Mohler, 1995; Kultas-Ilinsky et al., 1998), both thought to mediate tonic current in other neurons. To address whether any of the $\mathrm{GABA}_{\mathrm{A}} \mathrm{R}$-mediated effects observed in our current-clamp recordings were attributable to the activation of a tonic current, we performed whole-cell voltage-clamp recordings under conditions in which this current is typically identified, that is, when local levels of ambient GABA are elevated (Nusser and Mody, 2002; Stell and Mody, 2002; Semyanov et al., 2003; Stell et al., 2003; Wu et al., 2003). Using cesium chloride-containing intracellular pipettes, recordings were made at a holding potential of $-65 \mathrm{mV}$ from STN neurons within parasagittal slices in which presynaptic transmitter release was elevated with bath-applied 4-AP. This agent has been used to enhance activity at other central synapses, including those in the hippocampus (Segal, 1987; Otis and Mody, 1992), neostriatum (Flores-Hernandez et al., 1994), and dorsal column (Smith et al., 2000). Although typically considered a voltage-dependent potassium $\left(\mathrm{K}_{\mathrm{V}}\right)$ channel antagonist, 4-AP is also known to have less specific effects, particularly on intracellular calcium dynamics (Grimaldi et al., 2001). Used at concentrations $>1 \mathrm{~mm}, 4$-AP has been shown to elevate intracellular inositol triphosphate levels in cortical neurons, leading to calcium release from intracellular stores. With the aim of minimizing such interactions, 4-AP was used at a concentration of 25-50 $\mu \mathrm{M}$ in this study. 4-AP is proposed to increase transmission at the pallidosubthalamic synapse through an inhibition of $\mathrm{K}_{\mathrm{V}}$ channels suggested to be present in the axon and terminals of GP neurons (Rudy et al., 1999).

Voltage-clamp recordings from eight STN neurons in slices bathed in $25 \mu \mathrm{M} 4-\mathrm{AP}, 50 \mu \mathrm{M} \mathrm{APV}$, and $20 \mu \mathrm{M}$ DNQX, performed at room temperature to maintain a stable baseline over long periods, revealed large, frequent inward currents when cells were held at $-65 \mathrm{mV}$ (control mean frequency, $14.8 \pm 7.8 \mathrm{~Hz}$; control mean charge, $51.8 \pm 52.4 \mathrm{pC} / \mathrm{s}$ ). Figure 3 shows that subsequent fast application of $20 \mu \mathrm{M}$ GBZ significantly reduced the size and number of these phasic events (WSR tests; GBZ mean frequency, $0.2 \pm 0.4 \mathrm{~Hz} ; n=8 ; p=0.008 ; \mathrm{GBZ}$ mean charge, $0.2 \pm 0.2 \mathrm{pC} / \mathrm{s}$; $n=8 ; p=0.008$ ), with no accompanying change in baseline current (WSR test; baseline in control, $-53.0 \pm 28.2 \mathrm{pA}$; baseline in GBZ, $-50.6 \pm 28.4 \mathrm{pA} ; n=8 ; p=0.109)$. Because there is some uncertainty about the effectiveness of this concentration of GBZ in blocking tonic current (Yeung et al., 2003; Bieda and MacIver, 2004), we also fast-applied a mixture of a higher concentration $(100 \mu \mathrm{M})$ of GBZ in combination with $100 \mu \mathrm{M}$ picrotoxin to a subset of STN neurons. This treatment was also found to have no significant impact on baseline holding current (WSR test; baseline in control, $-63.2 \pm 9.2 \mathrm{pA}$; baseline in $100 \mu \mathrm{M} \mathrm{GBZ}$ and picrotoxin, $-61.5 \pm 8.4 \mathrm{pA} ; n=7 ; p=0.688)$. Because the impact of $\mathrm{GABA}_{\mathrm{A}} \mathrm{R}$ antagonists was similar in both cases, data were pooled (WSR test; baseline in control, $-57.8 \pm 26.0 \mathrm{pA}$; baseline in $\mathrm{GABA}_{\mathrm{A}} \mathrm{R}$ antagonists, $-55.7 \pm 25.4 \mathrm{pA} ; n=15 ; p=$ $0.135)$. To ensure that tonic current is indeed manifest under conditions of bath-applied 4-AP in neurons in which it has been identified previously, we recorded from cerebellar and dentate gyrus granule cells (Brickley et al., 1996; Stell and Mody, 2002; Stell et al., 2003). Under conditions of continually applied $25 \mu \mathrm{M}$ 4-AP, $50 \mu \mathrm{M} \mathrm{APV}$, and $20 \mu \mathrm{M}$ DNQX, subsequent rapid application of $20 \mu \mathrm{M}$ GBZ resulted in a significant shift in the baseline holding current of both cerebellar granule cells (WSR test; base- 
A

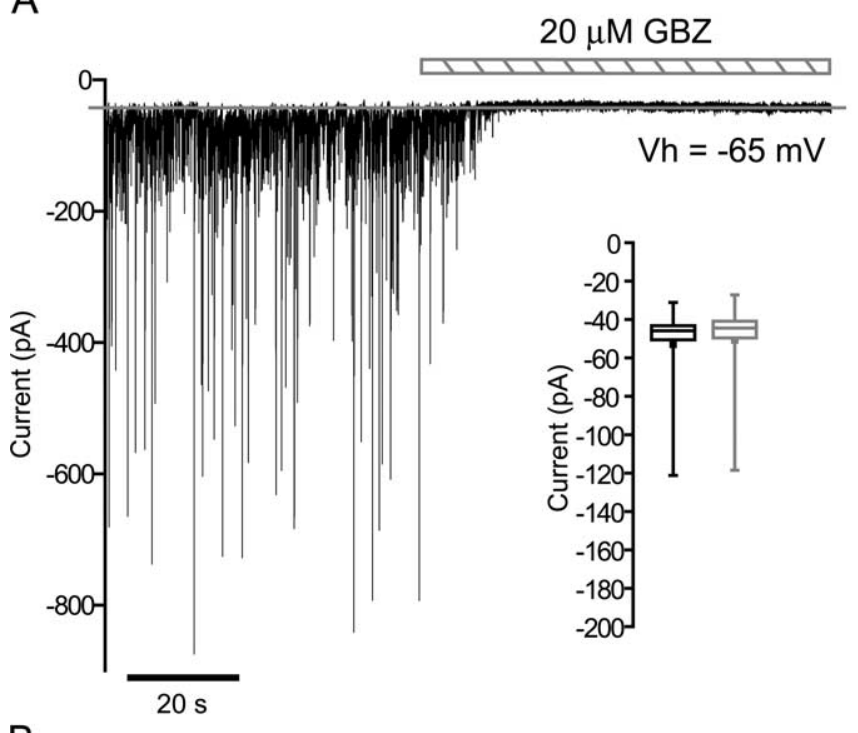

B

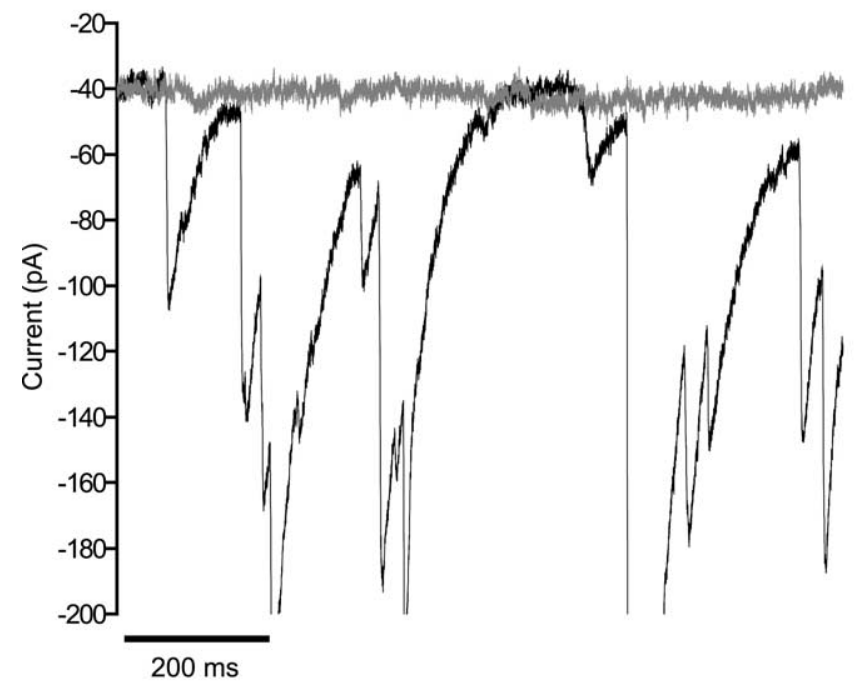

Figure 3. $G A B A_{A} R$-mediated tonic current is not observed in STN neurons. $A$, Representative example in which large, frequent inward currents recorded from an STN neuron in the presence of 4-AP were abolished by the fast application of GBZ, with no accompanying change in baseline holding current. The thin gray line represents average baseline holding current for predrug period. The inset indicates population data of average baseline current. Vh, Holding potential. $B$, Overlay of the first (black) and last (gray) second of data shown in $\boldsymbol{A}$ confirms that GBZ application does not influence baseline holding current.

line in control, $-45.6 \pm 25.9 \mathrm{pA}$; baseline in GBZ, $-25.2 \pm 13.5$ $\mathrm{pA} ; n=5 ; p=0.0431$ ) and hippocampal granule cells (WSR test; baseline in control, $-55.4 \pm 7.7 \mathrm{pA}$; baseline in GBZ, $-46.3 \pm$ $8.1 \mathrm{pA} ; n=6 ; p=0.031$ ) voltage-clamped at $-65 \mathrm{mV}$ (data not shown). Together, these data suggest that $\mathrm{GABA}_{\mathrm{A}} \mathrm{R}$-mediated tonic current is not present in STN neurons, even when presynaptic GABA release, which leads to the powerful, phasic activation of postsynaptic $\mathrm{GABA}_{\mathrm{A}}$ receptors, is elevated.

\section{$\mathrm{GABA}_{\mathrm{A}} \mathrm{R}$ and $\mathrm{GABA}_{\mathrm{B}} \mathrm{R}$ activation during conditions of elevated GABA release}

The 4-AP-mediated increase in pallidosubthalamic transmission also permitted us to test the hypothesis that subthalamic GAB$A_{B}$ Rs are preferentially activated when the level of pallidal input is elevated. Cesium chloride-based whole-cell voltage-clamp re- cordings from STN neurons within parasagittal slices bathed in $50 \mu \mathrm{M} 4-\mathrm{AP}$ and held at $37^{\circ} \mathrm{C}$ revealed large, frequent inward currents $(n=6$; control mean frequency, $43.9 \pm 24.4 \mathrm{~Hz}$; control mean charge, $54.5 \pm 35.8 \mathrm{pC} / \mathrm{s}$ ) (data not shown). Although these currents were recorded under conditions in which ionotropic glutamatergic transmission was blocked, they were highly sensitive to $\mathrm{GABA}_{\mathrm{A}} \mathrm{R}$ antagonists (WSR tests; GBZ mean frequency, $1.6 \pm 2.5 \mathrm{~Hz} ; n=6 ; p=0.031$; GBZ mean charge, $1.0 \pm 1.5 \mathrm{pC} / \mathrm{s}$; $n=6 ; p=0.031$ ), representing a $\sim 14$-fold greater mean GBZsensitive charge when compared with parasagittal slices maintained in APV and DNQX only $(53.5 \mathrm{pC} / \mathrm{s}$ in slices bathed in 4-AP vs $3.8 \mathrm{pC} / \mathrm{s}$ under control conditions). This was manifest in current-clamp recordings as barrages of IPSPs evident throughout the ISI (Fig. 4A). The eight STN neurons from which perforated-patch current-clamp recordings were obtained under conditions of bath-applied 4-AP, APV, and DNQX had an average firing rate of $7.2 \pm 6.6 \mathrm{~Hz}$. The single-spike activity recorded was irregular, with an average CV of $0.38 \pm 0.15$. Although it might be suggested that the relatively low firing rate observed is the product of a direct 4-AP-mediated blockade of $\mathrm{K}_{\mathrm{V}} 3$ channels expressed in STN neurons (Rudy et al., 1999; Wigmore and Lacey, 2000; Baranauskas et al., 2003), phasic GABAergic events contribute to the disruption in pace. Indeed, in recordings obtained from six neurons after the application of $20 \mu \mathrm{M}$ GBZ (Fig. $4 B, D)$, the average frequency of spontaneous activity was nearly doubled (WSR test; 4-AP frequency, $6.8 \pm 7.8 \mathrm{~Hz}$; GBZ frequency, $12.0 \pm 6.5 \mathrm{~Hz} ; n=6 ; p=0.031$ ). The precision of spontaneous activity was also significantly increased by this treatment (WSR test; 4-AP CV, $0.39 \pm 0.18$; GBZ CV, $0.11 \pm 0.05 ; n=$ $5 ; p=0.0431)$.

Additional application of CGP $(1 \mu \mathrm{M})$ was subsequently attempted, and recordings were obtained during conditions of both $\mathrm{GABA}_{\mathrm{A}} \mathrm{R}$ and $\mathrm{GABA}_{\mathrm{B}} \mathrm{R}$ blockade for five of the six neurons (Fig. 4C,E). Although this treatment had no effect on the precision of single-spike activity (WSR test; 4 -AP and GBZ CV, $0.11 \pm$ 0.05 ; CGP CV, $0.13 \pm 0.06 ; n=5 ; p=0.6858$ ), it led to an increase in the firing rate of every cell examined (WSR test; 4A-P and GBZ frequency, $11.7 \pm 7.2 \mathrm{~Hz}$; CGP frequency, $12.9 \pm 7.4$ $\mathrm{Hz} ; n=5 ; p=0.0431)$. Together, these data suggest that, under conditions in which synaptic GABA is elevated, activation of $\mathrm{GABA}_{\mathrm{A}} \mathrm{Rs}$ and $\mathrm{GABA}_{\mathrm{B}}$ Rs influences the frequency and precision of single-spike firing of individual STN neurons. This influence is weighted toward $\mathrm{GABA}_{\mathrm{A}} \mathrm{Rs}$, however, because their blockade more profoundly changes the manner in which STN neurons discharge, whereas subsequent blockade of $\mathrm{GABA}_{\mathrm{B}} \mathrm{Rs}$ had relatively minimal impact.

It should be noted that the average firing rate was not significantly different between spontaneous and 4-AP conditions when all GABAergic activity was blocked (MWU test; GBZ and CGP, $11.6 \pm 5.4 \mathrm{~Hz}$; $4-\mathrm{AP}, \mathrm{GBZ}$, and CGP, $12.9 \pm 7.4 \mathrm{~Hz} ; n=5 ; p=$ 0.905 ), nor was the average CV (MWU test; GBZ and CGP, $0.14 \pm 0.03 ; 4-\mathrm{AP}, \mathrm{GBZ}$, and CGP, $0.13 \pm 0.06 ; n=5 ; p=0.358$ ), suggesting that $25-50 \mu \mathrm{M} 4$-AP had no confounding influence on the intrinsic excitability of STN neurons.

\section{Postsynaptic $\mathrm{GABA}_{\mathrm{B}} \mathrm{R}$ activation leads to a transient reduction in STN activity}

To examine whether synchronous high-frequency activity of pallidosubthalamic fibers leads to the activation of postsynaptic $\mathrm{GABA}_{\mathrm{B}} \mathrm{Rs}$, perforated-patch current-clamp recordings were obtained from STN neurons within parasagittal slices while pallidal fibers were driven synchronously with high-frequency (20 pulses at $100 \mathrm{~Hz}$ ) electrical stimulation, before and after bath applica- 
A

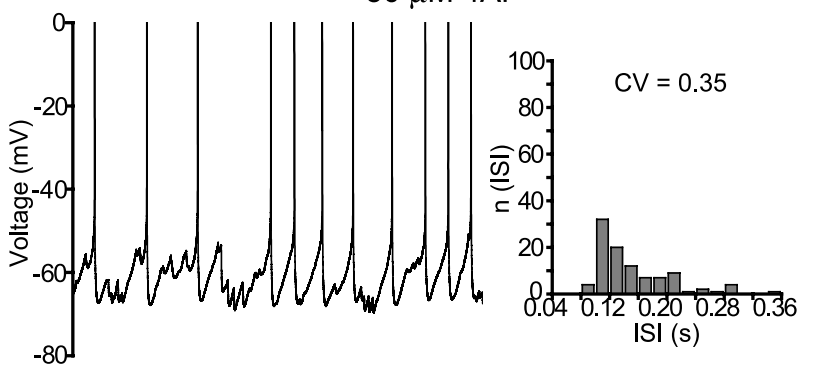

B

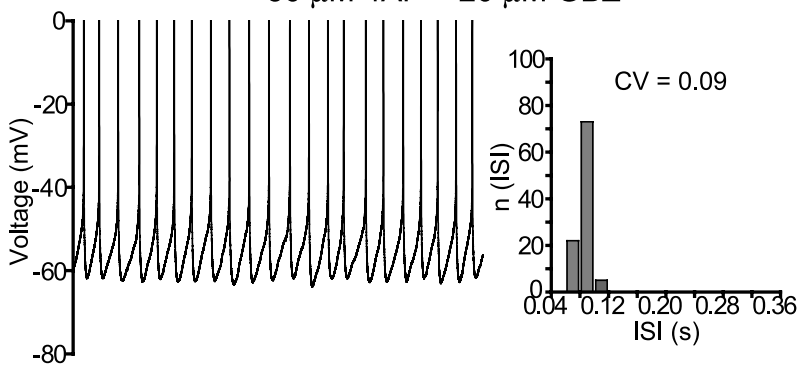

C

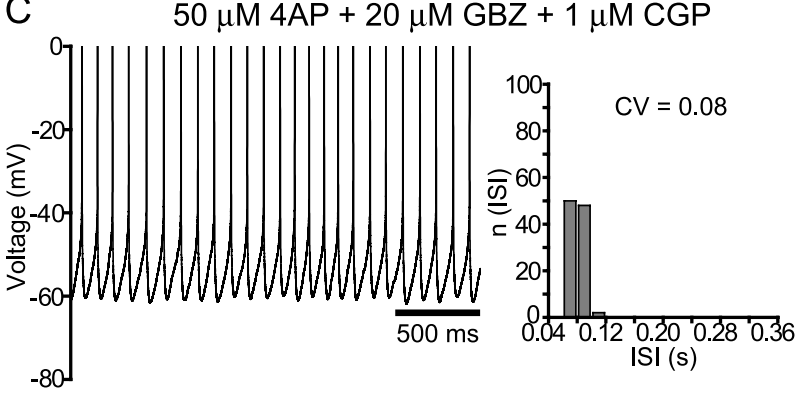

$50 \mu \mathrm{M} 4 \mathrm{AP}$

$\mathrm{SI}(\mathrm{s})$
$50 \mu \mathrm{M} 4 \mathrm{AP}+20 \mu \mathrm{M} \mathrm{GBZ}+1 \mu \mathrm{M}$ CGP
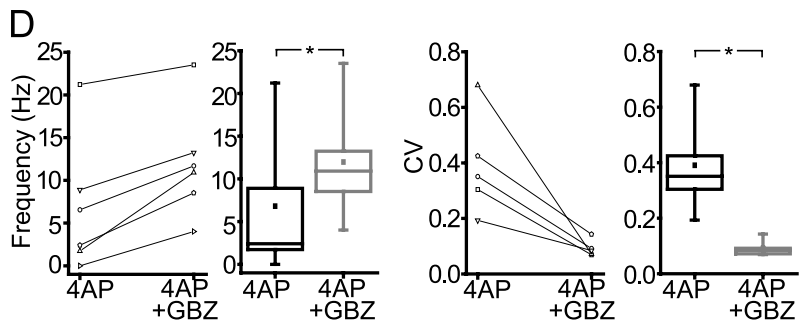

$\mathrm{E}$
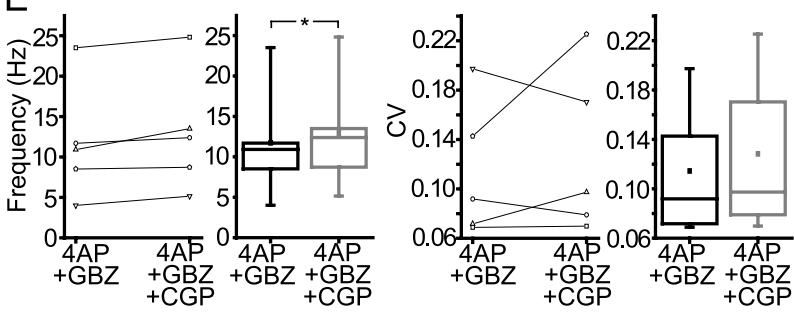

Figure 4. $G A B A_{A}$ and $G A B A_{B} R$ s are both activated during conditions of elevated GABA release, but $G A B A_{A} R$ activation influences the firing of STN neurons to a greater extent. $\boldsymbol{A}-\boldsymbol{C}$, Activity of a representative neuron under conditions in which presynaptic activity was elevated with 4-AP before and after subsequent block of ionotropic and metabotropic GABARs. The ISI histograms generated from 100 ISIs occurring during the respective conditions for this neuron are shown to the right. $A$, Both the pace and precision of single-spike firing were low (frequency, $6.6 \mathrm{~Hz} ; \mathrm{CV}, 0.35)$ under conditions of bath-applied $50 \mu \mathrm{m}$ 4-AP, which was associated with barrages of IPSPs. $B$, Blockade of $\mathrm{GABA}_{\mathrm{A}} \mathrm{Rs}$ with $20 \mu \mathrm{M} \mathrm{GBZ}$ increased the frequency and precision of activity (frequency, 11.7 Hz; CV, 0.09). C, Additional blockade of $G_{A B A}$ Rs with $1 \mu \mathrm{M}$ CGP had no additional influence on single-spike rhythmicity but slightly increased the frequency of activity (frequency, $12.4 \mathrm{~Hz}$; CV, 0.08). D, E, Population firing rate and $\mathrm{CV}$ data under each condition. ${ }^{*} p<0.05$. Calibration in $\boldsymbol{C}$ also applies to $\boldsymbol{A}$ and $\boldsymbol{B}$.

tion of a $\mathrm{GABA}_{\mathrm{B}} \mathrm{R}$ antagonist. Across the population of STN neurons from which recordings were obtained, in the presence of APV, DNQX, and GBZ, stimulation of the GP $(n=3)$ or internal capsule rostral to the STN $(n=9)$ resulted in a transient reduction in firing rate. This was evident as a trough in the peristimulus time histogram immediately after the stimulation period, during which firing was 2 SDs below the prestimulation level (Fig. 5Ai). The cumulative sum of the peristimulus time histogram also fell below 2 SDs of the mean prestimulation score within this period (Ellaway, 1978; Magill et al., 2004). The subsequent highfrequency response apparent in the raster displays of a subset of STN neurons will be the focus of the following section (see below). A range of stimulation-evoked reductions in firing were observed, with some neurons displaying less evident IPSPs and more modest suppressions in firing (Fig. 5Aii, sweep 1b), whereas others displayed larger IPSPs and more pronounced disruptions (Fig. 5Aii, sweep 2a). In the subset of neurons in which a pronounced, prolonged hyperpolarizing response was observed $(n=$ 7 ), the average latency of this response was $135.7 \pm 85.4 \mathrm{~ms}$, and the average time to the peak of the response was $310.9 \pm 105.3$ $\mathrm{ms}$. The average reversal potential of the response was found to be $-93.3 \pm 6.6 \mathrm{mV}$ in the three neurons in which stimulationevoked responses were obtained from a range of membrane potentials (predicted $E_{\mathrm{K}},-97.0 \mathrm{mV}$ ). Subsequent application of 1 $\mu \mathrm{M}$ CGP abolished the stimulation-evoked reduction in STN firing rate (Fig. $5 \mathrm{Bi}, \mathrm{Bii}$ ). These data demonstrate that synchronous, high-frequency activation of pallidosubthalamic fibers generates both subtle and overt postsynaptic $\mathrm{GABA}_{\mathrm{B}} \mathrm{R}$-mediated responses, which in each case lead to a transient reduction in the single-spike firing of STN neurons.

It should be noted that, under conditions of ionotropic glutamate, ionotropic GABA, and metabotropic GABA receptor blockade, high-frequency stimulation of the caudal internal capsule occasionally generated a transient increase in STN activity. Although we did not examine this further, it may be attributable to an activation of postsynaptic metabotropic glutamate receptors (Awad et al., 2000).

\section{Postsynaptic $\mathrm{GABA}_{\mathrm{B}} \mathrm{R}$ activation can contribute to rebound excitation in STN neurons}

Although high-frequency electrical stimulation of pallidal fibers was found to consistently lead to a $\mathrm{GABA}_{\mathrm{B}} \mathrm{R}$-mediated suppression of STN activity, it was also found to generate a subsequent period of elevated firing in a subset of the same neurons. Four of 20 STN neurons within parasagittal slices bathed in APV and DNQX in which tetanic stimulation was applied to the caudal GP $(n=10)$ or the rostral internal capsule $(n=10)$ responded with a rebound depolarization, associated with a burst of highfrequency firing (Fig. 6A). Notably, in all four cases, stimulation was applied to the internal capsule immediately rostral to the STN, presumably leading to the synchronization of a higher proportion of pallidal fibers. Such responses have previously been observed in STN neurons after bipolar electrical stimulation of the rostral internal capsule in sagittal preparations, and were attributed to the $\mathrm{GABA}_{\mathrm{A}}$ IPSP-mediated de-inactivation of class 3 voltage-dependent calcium $\left(\mathrm{Ca}_{\mathrm{V}} 3\right)$ channels (Bevan et al., 2002a). However, in that study, the putative contribution of metabotropic $\mathrm{GABA}_{\mathrm{B}}$ Rs to rebound burst firing was not examined because these receptors were blocked a priori. With GAB-

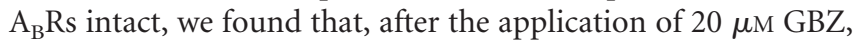
three of the four STN neurons still generated rebound bursts after the same tetanic stimulation protocols (Fig. $6 B$ ). In the three neurons in which rebound bursts persisted after $\mathrm{GABA}_{\mathrm{A}} \mathrm{R}$ block- 


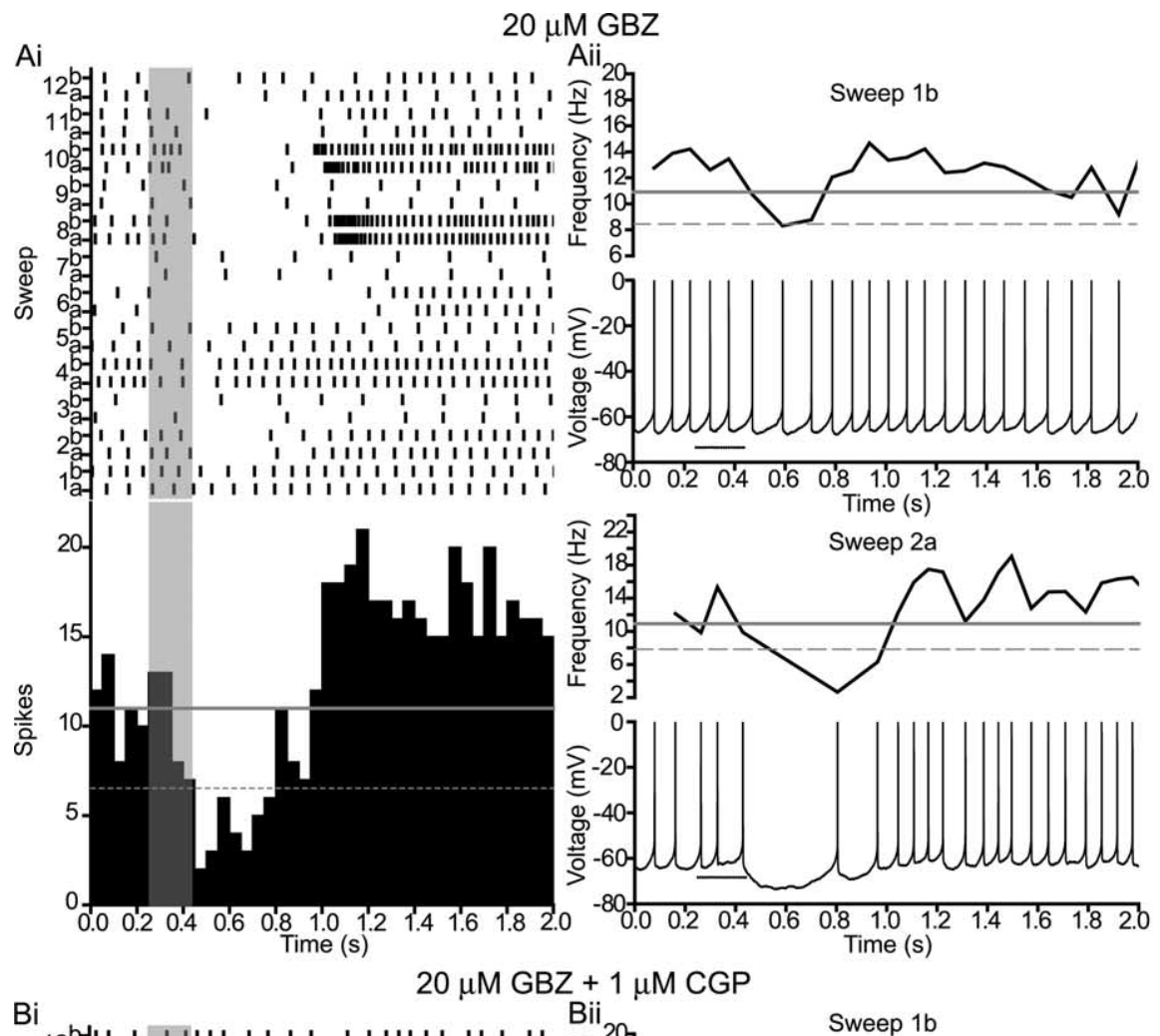

$\mathrm{Bi}$ befl, 1

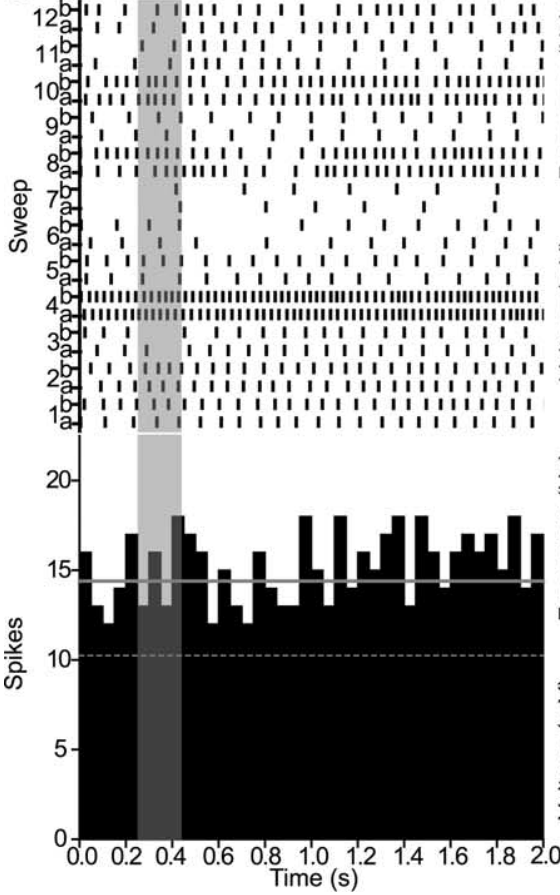

$\mathrm{Bii}_{20}$

는

소 18

청 14

\begin{tabular}{ll} 
인 & 10 \\
\hline
\end{tabular}

6

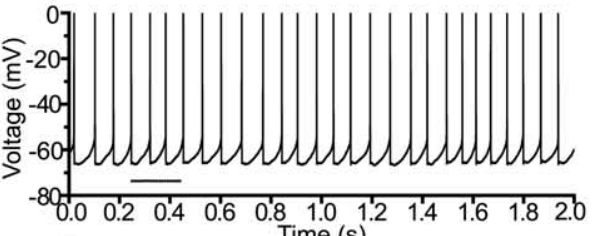

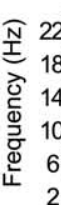

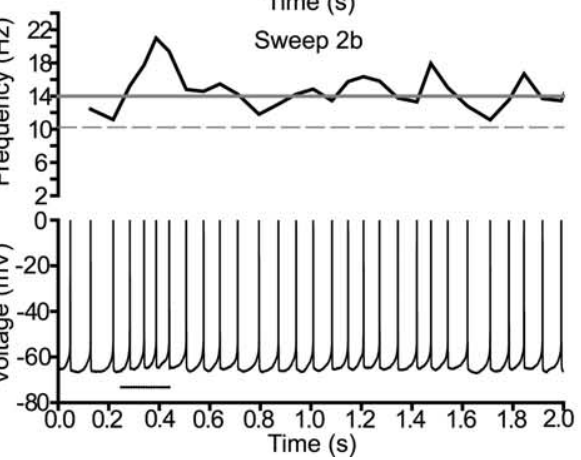

Figure 5. Stimulation of globus pallidus fibers leads to a transient $G A B A_{B} R$-mediated reduction in the firing rate of STN neurons. Ai, Aii, With $20 \mu \mathrm{M} \mathrm{GBZ}$ bath applied, tetanic stimulation of pallidal fibers consistently resulted in a transient reduction in STN firing. Ai, The stimulus-evoked pause in firing was apparent in peristimulus raster plots ( 12 neurons, 2 trials per neuron) and was manifest as a trough in the peristimulus time histogram after the period of applied stimulation (gray box). The solid gray line represents the average counts per bin before stimulation. The dashed gray line represents 2 SDs below this average. The highfrequency activity subsequent to the pause in firing apparent in sweeps 8 , a and b, and 10, a and b, is addressed in Results. Postsynaptic GABA $A_{B}$ activation can contribute to rebound excitation in STN neurons. Aii, Stimulus-evoked reductions in instantaneous firing rate in two separate neurons, illustrating the limits of the inhibitory effect observed. The solid gray line represents the average spontaneous firing rate. The dashed gray line represents the firing rate 2 SDs below this average. $\boldsymbol{B i}, \boldsymbol{B i i}, A f t e r$ the application of $1 \mu \mathrm{M}$ CGP, tetanic stimulation of pallidal fibers no longer produced a discernible reduction in firing. Bi, Raster plots and the accompanying peristimulus time histogram illustrate that ongoing activity was relatively unchanged by pallidal stimulation. Bii, Current-clamp recordings and accompanying analyses for the same neurons as in Aii, demonstrating the impact of high-frequency stimulation after CGP application. ade, the average length of high-frequency firing (defined as that three times above spontaneous activity) (Bevan et al., 2000, 2002a) was reduced by $38.5 \%$ (from 194.2 \pm 98.5 to $119.4 \pm 73.7 \mathrm{~ms})$, whereas the peak frequency attained during the burst period was reduced by $24.4 \%$ (from 98.4 \pm 42.9 to $74.3 \pm 43.9 \mathrm{~Hz}$ ). Note that the depth of hyperpolarization and resulting intensity and duration of high-frequency firing were also related to the number of pulses in the stimulation train (Fig. 6). On subsequent application of $1 \mu \mathrm{M}$ CGP, high-frequency stimulation of the rostral internal capsule no longer evoked an IPSP or consequent rebound depolarization, indicating that the activation of postsynaptic $\mathrm{GABA}_{\mathrm{B}}$ Rs is sufficient to generate such responses in STN neurons (Fig. 6C). Importantly, the application of a brief hyperpolarizing current pulse was still able to generate rebound burst responses in STN neurons bathed in CGP, indicating that the failure to generate rebounds with synaptic stimulation was not the consequence of a confounding action of this agent on rebound generating mechanisms intrinsic to STN neurons.

\section{Discussion}

Pallidosubthalamic connections are preserved in the parasagittal slice Our first objective was to maintain pallidosubthalamic connections in a brain slice. To achieve this, we obtained slices from mice, in which we may have retained up to one-fourth and one-half of the native GP and STN, respectively (Paxinos and Franklin, 2001). Together, anatomical and electrophysiological observations suggest that intact pallidosubthalamic projections were maintained. Deposits of biocytin in the GP of these slices consistently labeled fibers and somata in the STN. GP neurons were also spontaneously active, and action potential-dependent GABAergic IPSCs were recorded from STN neurons. Finally, electrical stimulation of the GP produced GABAR-mediated responses in STN neurons.

Spontaneous pallidosubthalamic activity influences STN firing through the phasic activation of postsynaptic $\mathrm{GABA}_{\mathrm{A}} \mathrm{Rs}$

By performing current-clamp recordings of STN neurons within parasagittal slices, we were able to determine the impact of spontaneously occurring pallidosubthalamic transmission on postsynaptic activity. We found that GABA released under these conditions was sufficient to activate postsynaptic $\mathrm{GABA}_{\mathrm{A}} \mathrm{Rs}$, leading to a $20 \%$ 
reduction in firing rate and a $40 \%$ reduction in the precision of firing. Tonic activation of $\mathrm{GABA}_{\mathrm{A}}$ Rs was never observed in STN neurons. Therefore, the change in single-spike activity observed on $\mathrm{GABA}_{\mathrm{A}} \mathrm{R}$ blockade was entirely attributable to the blockade of phasic events. Spontaneous pallidal input did not sufficiently activate postsynaptic $\mathrm{GABA}_{\mathrm{B}}$ Rs to influence STN firing. Similar observations have been made in other in vitro preparations in which spontaneous GABAergic transmission has been preserved (Hausser and Clark, 1997; Kononenko and Dudek, 2004).

\section{Elevated/synchronous} pallidosubthalamic transmission influences STN firing through actions at postsynaptic $\mathrm{GABA}_{\mathrm{A}}$ Rs and $\mathrm{GABA}_{\mathrm{B}} \mathrm{Rs}$

Applications of selective agonists have suggested that there are functional $\mathrm{GABA}_{\mathrm{B}}$ Rs on STN neurons (Shen and Johnson, 2001; Urbain et al., 2002), but the conditions under which these receptors are activated by the synaptic release of GABA have not been addressed. Under conditions of elevated GABA release (4$\mathrm{AP})$, pallidal input primarily influenced STN firing through barrages of $\mathrm{GABA}_{\mathrm{A}} \mathrm{R}$ mediated IPSPs, but postsynaptic GAB$A_{B} R$ activation also reduced the firing of STN neurons by $10 \%$. Postsynaptic GAB$\mathrm{A}_{\mathrm{B}}$ Rs were also activated by tetanic, highfrequency stimulation of the caudal GP/ internal capsule. Because the minimum distance between two poles of stimulation was $240 \mu \mathrm{m}$, a large proportion of pallidal axons were presumably activated simultaneously. Stimulation-evoked $\mathrm{GABA}_{\mathrm{B}} \mathrm{R}$ activation led to a transient reduction in postsynaptic firing, but could also lead to a subsequent increase in firing by generating sufficient hyperpolarization to produce rebound bursts.

Together, these data suggest that postsynaptic $\mathrm{GABA}_{\mathrm{B}} \mathrm{Rs}$ are activated only during periods of elevated/synchronized GP activity that lead to the spillover of GABA at pallidosubthalamic synapses. This proposition is consistent with anatomical assessments that suggest that high levels of various $\mathrm{GABA}_{\mathrm{A}} \mathrm{R}$ subunits are expressed in the STN (Wisden et al., 1992; Fritschy and Mohler, 1995; Kultas-Ilinsky et al., 1998; Smith et al., 2001), whereas only moderate immunoreactivity has been observed for $\mathrm{GABA}_{\mathrm{B}} \mathrm{R}$ subunits (Billinton et al., 2000; Charara et al., 2000; Smith et al., 2001). Moreover, whereas the majority of $\mathrm{GABA}_{\mathrm{A}} \mathrm{Rs}$ are in the main body of symmetrical synapses, $77 \%$ of membrane-bound $\mathrm{GABA}_{\mathrm{B}}$ Rs are extrasynaptic (Galvan et al., 2004). Our observations are similar to those made in other brain regions in which a local increase in GABA concentration is necessary for the activation of extrasynaptic GABA ${ }_{B}$ Rs (Isaacson et al., 1993; Mody et al., 1994; Mitchell and Silver, 2000; Scanziani, 2000). Although GABA is typically elevated to levels sufficient for the activation of postsynaptic $\mathrm{GABA}_{\mathrm{B}}$ Rs through the blockade of GABA uptake or
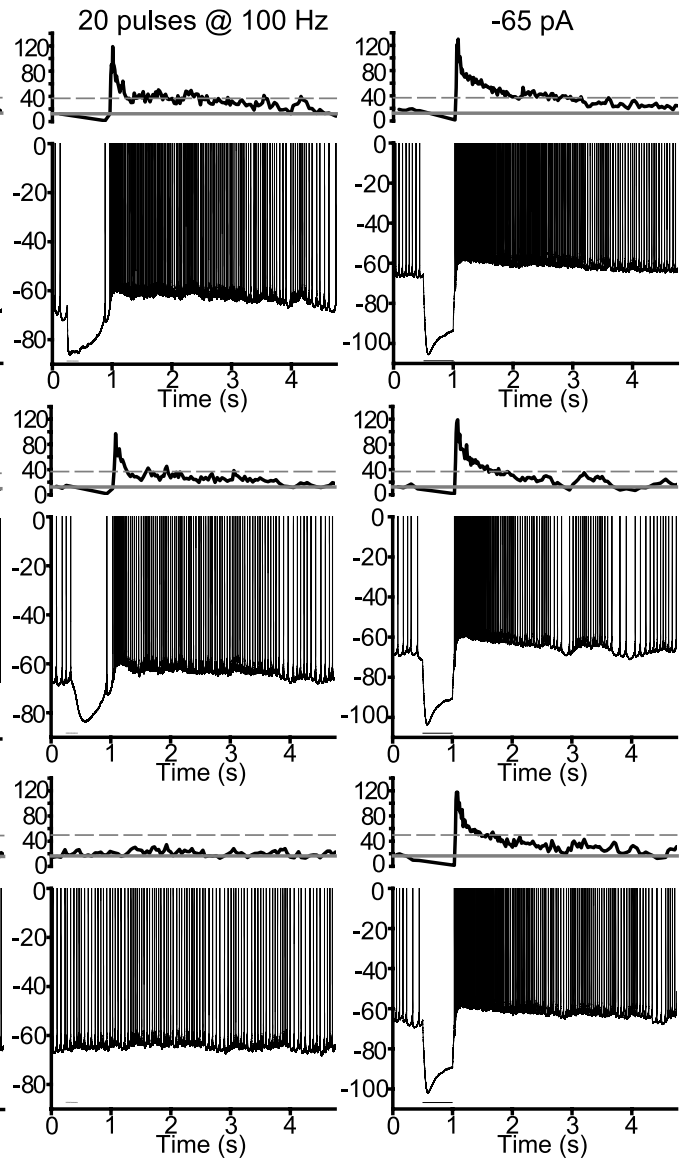

Figure 6. Synaptic activation of $G A B A_{B}$ Rs generates rebound burst firing in STN neurons. $\boldsymbol{A}$, Activity of a representative neuron in which tetanic stimulation applied to the caudal internal capsule evoked a transient hyperpolarization followed by a rebound olarization and an associated period of high-frequency firing. Longer trains of stimulation generated more intense rebound 列 gray line represents average spontaneous firing rate. The dashed gray line represents three times the average firing rate. $\boldsymbol{B}$ frequency rebound burst firing persisted in response to both stimulation of the internal capsule and negative current accompanying rebound burst response to tetanic stimulation. Rebound burst firing was still evoked on the removal of a $-65 \mathrm{pA}$ current step under these conditions.

tetanic electrical stimulation, in vitro recordings from hippocampal and thalamic synapses demonstrate that this also occurs when presynaptic neurons are synchronously active during network rhythms (Kim et al., 1997; Scanziani, 2000; Jacobsen et al., 2001).

\section{Functional implications of postsynaptic GABAR activation}

Mammalian STN neurons fire between 10 and $50 \mathrm{~Hz}$ in an irregular pattern (Wichmann et al., 1994; Levy et al., 2000; Urbain et al., 2002; Soares et al., 2004). Under these conditions, local application of $\mathrm{GABA}_{\mathrm{A}} \mathrm{R}$ antagonists increases STN activity (RouzaireDubois et al., 1980; Urbain et al., 2002). In contrast, $G_{A B A} R$ antagonists have no effect. However, interpretation of in vivo pharmacological manipulations can be difficult: drugs are applied at a distance from the recorded cell; the effective drug concentration is unknown; and multisynaptic effects are possible. By manipulating pallidosubthalamic transmission in vitro, we confirmed that, under spontaneous conditions, GABAergic input from the GP regulates STN activity primarily through the phasic activation of postsynaptic $\mathrm{GABA}_{\mathrm{A}} \mathrm{Rs}$, and not $\mathrm{GABA}_{\mathrm{B}} \mathrm{Rs}$.

Corticosubthalamic fibers provide a major excitatory input to the STN, but after the removal of this input, STN neurons discharge in an irregular single-spike manner, with an average $\mathrm{CV}$ of 
0.58 (Magill et al., 2001). Our data suggest that inhibitory input from the GP accounts for much of the irregular nature of STN firing in vivo. In vitro and in vivo data indicate that STN neurons are active despite receiving continuous input from the GP (even in the absence of glutamatergic input) (Bevan and Wilson, 1999; Magill et al., 2000, 2001). Incomplete silencing of postsynaptic neurons is a common feature of information transfer at pallidal synapses, because other GP efferents maintain high firing rates in awake animals (Wichmann et al., 1999; Raz et al., 2000; Wichmann and Kliem, 2004). Pallidal inhibition may be less effective than predicted for a variety of reasons. Normally, GP firing is not synchronized or correlated (Nini et al., 1995; Raz et al., 2000; Soares et al., 2004). As such, GABA $\mathrm{A}$-mediated IPSPs are less likely to summate and postsynaptic $\mathrm{GABA}_{\mathrm{B}}$ Rs may not be activated sufficiently to suppress firing. Presynaptic inhibition of GABA release (Shen and Johnson, 2000, 2001; Chen and Yung, 2005) and postsynaptic receptor saturation/desensitization (Nusser et al., 1997; Overstreet et al., 2000) are also possible. Finally, postsynaptic GABAR-mediated hyperpolarization could engage hyperpolarization-activated cyclic-nucleotide gated channels, $\mathrm{Ca}_{\mathrm{V}} 3$ channels, and/or $\mathrm{Na}_{\mathrm{V}}$ channels that mediate inward currents that could counteract inhibition (Mainen and Sejnowski, 1995; Huguenard, 1996; McCormick and Bal, 1997). Because persistent inhibitory input from the GP does not silence STN neurons, their firing can be both upregulated and downregulated, making the nucleus a dynamic controller of basal ganglia network activity.

In vitro manipulations demonstrated that $\mathrm{GABA}_{\mathrm{B}} \mathrm{Rs}$ can be sufficiently activated to impact firing when pallidosubthalamic activity is elevated. In vivo, subsets of GP neurons momentarily increase their firing after cortical stimulation meant to simulate a descending motor command. This excitation results in feedback inhibition (Ryan and Clark, 1992; Nambu et al., 2000; Kolomiets et al., 2001; Kita et al., 2004) and brief synchronization of the STN (Magill et al., 2004). Although in vivo recordings suggest that this inhibition is mediated primarily by $\mathrm{GABA}_{\mathrm{A}} \mathrm{Rs}$ (Rouzaire-Dubois et al., 1980; Kita et al., 1983), the contribution of $\mathrm{GABA}_{\mathrm{B}} \mathrm{Rs}$ has not been examined. Computer simulations suggest that cortically driven elevated firing in GP neurons may lead to $G_{A B A} R$ mediated hyperpolarization and subsequent rebound burst firing in STN neurons, which is necessary for switching between competing motor programs (Rubchinsky et al., 2003). Our in vitro results demonstrate that such a mechanism is plausible and provide motivation for in vivo study.

\section{Implications for pathological activity}

In idiopathic and experimental models of PD, populations of STN and GP neurons display correlated, rhythmic burst firing which may underlie, in part, motor symptoms (Bevan et al., 2002b; Amirnovin et al., 2004; Dostrovsky and Bergman, 2004). Computer modeling (Terman et al., 2002), in vitro (Plenz and Kital, 1999; Bevan et al., 2002a), and in vivo (Paz et al., 2005) studies suggest that burst firing in STN neurons is driven, in part, by rebound depolarization that can be produced after barrages of $\mathrm{GABA}_{\mathrm{A}} \mathrm{R}$-mediated IPSPs arising from pallidal fibers. These barrages were produced in vitro through synchronous, highfrequency activation of these fibers. We consistently found that synchronous, high-frequency activation of pallidal fibers could also activate postsynaptic metabotropic $\mathrm{GABA}_{\mathrm{B}}$ Rs. This had a considerable synergistic effect: the duration and intensity of highfrequency rebound burst firing in STN neurons were consistently greater when both $\mathrm{GABA}_{\mathrm{A}}$ Rs and $\mathrm{GABA}_{\mathrm{B}}$ Rs were activated. The recruitment of postsynaptic $G_{A B A} R$-mediated activity may therefore be an important additional mechanism through which burst firing in the parkinsonian STN-GP network is generated. Given the relative time courses of ionotropic and metabotropic GABAR-mediated currents, $\mathrm{GABA}_{\mathrm{B}} \mathrm{R}$-mediated rebound bursts may reduce the frequency of $\mathrm{GABA}_{\mathrm{A}} \mathrm{R}$-mediated rhythms within the STN-GP network (as in other systems) (Kim et al., 1997; Scanziani, 2000; Sohal and Huguenard, 2003), which may in turn contribute to the range of oscillatory frequencies observed in parkinsonian animals and human patients (Bevan et al., 2002b; Brown, 2003; Dostrovsky and Bergman, 2004; Hutchison et al., 2004).

Electron microscopic analyses performed by Galvan et al. (2004) indicate that $64 \%$ of $\mathrm{GABA}_{\mathrm{B}} \mathrm{Rs}$ are cytoplasmic and not expressed in the plasmalemma. As these authors suggest, the insertion of these receptors into the cell membrane may be regulated dynamically. Indeed, $\mathrm{GABA}_{\mathrm{B}} \mathrm{R}$ mRNA expression increases in the STN in an animal model of PD (Johnston and Duty, 2003). Therefore, the impact of postsynaptic $\mathrm{GABA}_{\mathrm{B}} \mathrm{R}$ activation in the parkinsonian basal ganglia may be of even greater significance than that established in our study of unlesioned animals. The findings described here should provide a foundation on which the principles of pallidosubthalamic transmission in parkinsonian animals can be addressed.

\section{References}

Amirnovin R, Williams ZM, Cosgrove GR, Eskandar EN (2004) Visually guided movements suppress subthalamic oscillations in Parkinson's disease patients. J Neurosci 24:11302-11306.

Awad H, Hubert GW, Smith Y, Levey AI, Conn PJ (2000) Activation of metabotropic glutamate receptor 5 has direct excitatory effects and potentiates NMDA receptor currents in neurons of the subthalamic nucleus. J Neurosci 20:7871-7879.

Baranauskas G, Tkatch T, Nagata K, Yeh JZ, Surmeier DJ (2003) Kv3.4 subunits enhance the repolarizing efficiency of Kv3.1 channels in fast-spiking neurons. Nat Neurosci 6:258-266.

Barry PH (1994) JPCalc, a software package for calculating liquid junction potential corrections in patch-clamp, intracellular, epithelial and bilayer measurements and for correcting junction potential measurements. J Neurosci Methods 51:107-116.

Baufreton J, Garret M, Dovero S, Dufy B, Bioulac B, Taupignon A (2001) Activation of $\mathrm{GABA}_{\mathrm{A}}$ receptors in subthalamic neurons in vitro: properties of native receptors and inhibition mechanisms. J Neurophysiol 86:75-85.

Bergman H, Wichmann T, Karmon B, DeLong MR (1994) The primate subthalamic nucleus. II. Neuronal activity in the MPTP model of parkinsonism. J Neurophysiol 72:507-520.

Bevan MD, Wilson CJ (1999) Mechanisms underlying spontaneous oscillation and rhythmic firing in rat subthalamic neurons. J Neurosci 19:7617-7628.

Bevan MD, Clarke NP, Bolam JP (1997) Synaptic integration of functionally diverse pallidal information in the entopeduncular nucleus and subthalamic nucleus in the rat. J Neurosci 17:308-324.

Bevan MD, Booth PA, Eaton SA, Bolam JP (1998) Selective innervation of neostriatal interneurons by a subclass of neuron in the globus pallidus of the rat. J Neurosci 18:9438-9452.

Bevan MD, Wilson CJ, Bolam JP, Magill PJ (2000) Equilibrium potential of $\mathrm{GABA}_{\mathrm{A}}$ current and implications for rebound burst firing in rat subthalamic neurons in vitro. J Neurophysiol 83:3169-3172.

Bevan MD, Magill PJ, Hallworth NE, Bolam JP, Wilson CJ (2002a) Regulation of the timing and pattern of action potential generation in rat subthalamic neurons in vitro by GABA-A IPSPs. J Neurophysiol 87:1348-1362.

Bevan MD, Magill PJ, Terman D, Bolam JP, Wilson CJ (2002b) Move to the rhythm: oscillations in the subthalamic nucleus-external globus pallidus network. Trends Neurosci 25:525-531.

Bieda MC, MacIver MB (2004) Major role for tonic $\mathrm{GABA}_{\mathrm{A}}$ conductances in anesthetic suppression of intrinsic neuronal excitability. J Neurophysiol 92:1658-1667.

Billinton A, Ige AO, Wise A, White JH, Disney GH, Marshall FH, Waldvogel HJ, 
Faull RL, Emson PC (2000) GABA $_{\mathrm{B}}$ receptor heterodimer-component localisation in human brain. Brain Res Mol Brain Res 77:111-124.

Brickley SG, Cull-Candy SG, Farrant M (1996) Development of a tonic form of synaptic inhibition in rat cerebellar granule cells resulting from persistent activation of GABAA receptors. J Physiol (Lond) 497:753-759.

Brown P (2003) Oscillatory nature of human basal ganglia activity: relationship to the pathophysiology of Parkinson's disease. Mov Disord 18:357-363.

Caraiscos VB, Elliott EM, You-Ten KE, Cheng VY, Belelli D, Newell JG, Jackson MF, Lambert JJ, Rosahl TW, Wafford KA, MacDonald JF, Orser BA (2004) Tonic inhibition in mouse hippocampal CA1 pyramidal neurons is mediated by $\alpha 5$ subunit-containing $\gamma$-aminobutyric acid type $\mathrm{A}$ receptors. Proc Natl Acad Sci USA 101:3662-3667.

Chan CS, Shigemoto R, Mercer JN, Surmeier DJ (2004) HCN2 and HCN1 channels govern the regularity of autonomous pacemaking and synaptic resetting in globus pallidus neurons. J Neurosci 24:9921-9932.

Charara A, Heilman TC, Levey AI, Smith Y (2000) Pre- and postsynaptic localization of $\mathrm{GABA}_{\mathrm{B}}$ receptors in the basal ganglia in monkeys. Neuroscience 95:127-140.

Chen L, Yung WH (2005) Tonic activation of presynaptic GABA receptors on rat pallidosubthalamic terminals. Acta Pharmacol Sin 26:10-16.

Cooper AJ, Stanford IM (2000) Electrophysiological and morphological characteristics of three subtypes of rat globus pallidus neurone in vitro. J Physiol (Lond) 527:291-304.

DeLong MR (1971) Activity of pallidal neurons during movement. J Neurophysiol 34:414-427.

Dostrovsky J, Bergman H (2004) Oscillatory activity in the basal gangliarelationship to normal physiology and pathophysiology. Brain 127:721-722.

Ellaway PH (1978) Cumulative sum technique and its application to the analysis of peristimulus time histograms. Electroencephalogr Clin Neurophysiol 45:302-304.

Flores-Hernandez J, Galarraga E, Pineda JC, Bargas J (1994) Patterns of excitatory and inhibitory synaptic transmission in the rat neostriatum as revealed by 4-AP. J Neurophysiol 72:2246-2256.

Fritschy JM, Mohler H (1995) GABAA-receptor heterogeneity in the adult rat brain: differential regional and cellular distribution of seven major subunits. J Comp Neurol 359:154-194.

Galvan A, Charara A, Pare JF, Levey AI, Smith Y (2004) Differential subcellular distribution of $\mathrm{GABA}_{\mathrm{A}}$ and $\mathrm{GABA}_{\mathrm{B}}$ receptors in the monkey subthalamic nucleus. Neuroscience 127:709-721.

Gardiner TW, Kitai ST (1992) Single-unit activity in the globus pallidus and neostriatum of the rat during performance of a trained head movement. Exp Brain Res 88:517-530.

Gillies A, Willshaw D, Li Z (2002) Subthalamic-pallidal interactions are critical in determining normal and abnormal functioning of the basal ganglia. Proc Biol Sci 22:545-551.

Grimaldi M, Atzori M, Ray P, Alkon DL (2001) Mobilization of calcium from intracellular stores, potentiation of neurotransmitter-induced calcium transients, and capacitative calcium entry by 4 -aminopyridine. J Neurosci 21:3135-3143.

Hallworth NE, Wilson CJ, Bevan MD (2003) Apamin-sensitive small conductance calcium-activated potassium channels, through their selective coupling to voltage-gated calcium channels, are critical determinants of the precision, pace, and pattern of action potential generation in rat subthalamic nucleus neurons in vitro. J Neurosci 20:7525-7542.

Hausser M, Clark BA (1997) Tonic synaptic inhibition modulates neuronal output pattern and spatiotemporal synaptic integration. Neuron 19:665-678.

Huguenard JR (1996) Low-threshold calcium currents in central nervous system neurons. Annu Rev Physiol 58:329-348.

Hutchison WD, Allan RJ, Opitz H, Levy R, Dostrovsky JO, Lang AE, Lozano AM (1998) Neurophysiological identification of the subthalamic nucleus in surgery for Parkinson's disease. Ann Neurol 44:622-628.

Hutchison WD, Dostrovsky JO, Walters JR, Courtemanche R, Boraud T, Goldberg J, Brown P (2004) Neuronal oscillations in the basal ganglia and movement disorders: evidence from whole animal and human recordings. J Neurosci 24:9240-9243.

Isaacson JS (2000) Spillover in the spotlight. Curr Biol 10:R475-R477.

Isaacson JS, Solis JM, Nicoll RA (1993) Local and diffuse synaptic actions of GABA in the hippocampus. Neuron 10:165-175.

Jacobsen RB, Ulrich D, Huguenard JR (2001) $\mathrm{GABA}_{\mathrm{B}}$ and NMDA receptors contribute to spindle-like oscillations in rat thalamus in vitro. J Neurophysiol 86:1365-1375.

Johnston T, Duty S (2003) Changes in $\mathrm{GABA}_{\mathrm{B}}$ receptor mRNA expression in the rodent basal ganglia and thalamus following lesion of the nigrostriatal pathway. Neuroscience 120:1027-1035.

Kim U, Sanchez-Vives MV, McCormick DA (1997) Functional dynamics of GABAergic inhibition in the thalamus. Science 278:130-134.

Kita H, Chang HT, Kitai ST (1983) Pallidal inputs to subthalamus: intracellular analysis. Brain Res 264:255-265.

Kita H, Nambu A, Kaneda K, Tachibana Y, Takada M (2004) Role of ionotropic glutamatergic and GABAergic inputs on the firing activity of neurons in the external pallidum in awake monkeys. J Neurophysiol 92:3069-3084.

Kolomiets BP, Deniau JM, Mailly P, Menetrey A, Glowinski J, Thierry AM (2001) Segregation and convergence of information flow through the cortico-subthalamic pathways. J Neurosci 21:5764-5772.

Kononenko NI, Dudek FE (2004) Mechanism of irregular firing of suprachiasmatic nucleus neurons in rat hypothalamic slices. J Neurophysiol 91:267-273.

Kultas-Ilinsky K, Leontiev V, Whiting PJ (1998) Expression of $10 \mathrm{GABA}_{\mathrm{A}}$ receptor subunit messenger RNAs in the motor-related thalamic nuclei and basal ganglia of Macaca mulatta studied with in situ hybridization histochemistry. Neuroscience 85:179-204.

Levy R, Hutchison WD, Lozano AM, Dostrovsky JO (2000) High-frequency synchronization of neuronal activity in the subthalamic nucleus of parkinsonian patients with limb tremor. J Neurosci 20:7766-7775.

Levy R, Hutchison WD, Lozano AM, Dostrovsky JO (2002) Synchronized neuronal discharge in the basal ganglia of parkinsonian patients is limited to oscillatory activity. J Neurosci 22:2855-2861.

Magill PJ, Bolam JP, Bevan MD (2000) Relationship of activity in the subthalamic nucleus-globus pallidus network to cortical electroencephalogram. J Neurosci 20:820-833.

Magill PJ, Bolam JP, Bevan MD (2001) Dopamine regulates the impact of the cerebral cortex on the subthalamic nucleus-globus pallidus network. Neuroscience 106:313-330.

Magill PJ, Sharott A, Bevan MD, Brown P, Bolam JP (2004) Synchronous unit activity and local field potentials evoked in the subthalamic nucleus by cortical stimulation. J Neurophysiol 92:700-714.

Mainen ZF, Sejnowski TJ (1995) Reliability of spike timing in neocortical neurons. Science 268:1503-1506.

McCormick DA, Bal T (1997) Sleep and arousal: thalamocortical mechanisms. Annu Rev Neurosci 20:185-215.

Mitchell SJ, Silver RA (2000) GABA spillover from single inhibitory axons suppresses low-frequency excitatory transmission at the cerebellar glomerulus. J Neurosci 20:8651-8658.

Mody I (2001) Distinguishing between $\mathrm{GABA}_{\mathrm{A}}$ receptors responsible for tonic and phasic conductances. Neurochem Res 26:907-913.

Mody I, De Koninck Y, Otis TS, Soltesz I (1994) Bridging the cleft at GABA synapses in the brain. Trends Neurosci 17:517-525.

Nambu A, Llinas R (1994) Electrophysiology of globus pallidus neurons in vitro. J Neurophysiol 72:1127-1139.

Nambu A, Tokuno H, Hamada I, Kita H, Imanishi M, Akazawa T, Ikeuchi Y, Hasegawa N (2000) Excitatory cortical inputs to pallidal neurons via the subthalamic nucleus in the monkey. J Neurophysiol 84:289-300.

Nini A, Feingold A, Slovin H, Bergman H (1995) Neurons in the globus pallidus do not show correlated activity in the normal monkey, but phaselocked oscillations appear in the MPTP model of parkinsonism. J Neurophysiol 74:1800-1805.

Nusser Z, Mody I (2002) Selective modulation of tonic and phasic inhibitions in dentate gyrus granule cells. J Neurophysiol 87:2624-2628.

Nusser Z, Cull-Candy S, Farrant M (1997) Differences in synaptic GABA receptor number underlie variation in GABA mini amplitude. Neuron 19:697-709.

Otis TS, Mody I (1992) Differential activation of GABAA and GABAB receptors by spontaneously released transmitter. J Neurophysiol 67:227-235.

Overstreet LS, Jones MV, Westbrook GL (2000) Slow desensitization regulates the availability of synaptic $\mathrm{GABA}_{\mathrm{A}}$ receptors. J Neurosci 20:7914-7921.

Paxinos G, Franklin KBJ (2001) The mouse brain in stereotaxic coordinates, Ed 2. San Diego: Academic.

Paz JT, Deniau JM, Charpier S (2005) Rhythmic bursting in the corticosubthalamo-pallidal network during spontaneous genetically determined spike and wave discharges. J Neurosci 25:2092-2101. 
Plenz D, Kital ST (1999) A basal ganglia pacemaker formed by the subthalamic nucleus and external globus pallidus. Nature 400:677-682.

Raz A, Vaadia E, Bergman H (2000) Firing patterns and correlations of spontaneous discharge of pallidal neurons in the normal and the tremulous 1-methyl-4-phenyl-1,2,3,6-tetrahydropyridine vervet model of parkinsonism. J Neurosci 20:8559-8571.

Rouzaire-Dubois B, Hammond C, Hamon B, Feger J (1980) Pharmacological blockade of the globus pallidus-induced inhibitory response of subthalamic cells in the rat. Brain Res 200:321-329.

Rubchinsky LL, Kopell N, Sigvardt KA (2003) Modeling facilitation and inhibition of competing motor programs in basal ganglia subthalamic nucleus-pallidal circuits. Proc Natl Acad Sci USA 100:14427-14432.

Rudy B, Chow A, Lau D, Amarillo Y, Ozaita A, Saganich M, Moreno H, Nadal MS, Hernandez-Pineda R, Hernandez-Cruz A, Erisir A, Leonard C, VegaSaenz de Miera E (1999) Contributions of Kv3 channels to neuronal excitability. Ann NY Acad Sci 868:304-343.

Ryan LJ, Clark KB (1992) Alteration of neuronal responses in the subthalamic nucleus following globus pallidus and neostriatal lesions in rats. Brain Res Bull 29:319-327.

Sanchez-Vives MV, McCormick DA (2000) Cellular and network mechanisms of rhythmic recurrent activity in neocortex. Nat Neurosci 3:1027-1034.

Scanziani M (2000) GABA spillover activates postsynaptic GABA $_{B}$ receptors to control rhythmic hippocampal activity. Neuron 25:673-681.

Segal M (1987) Repetitive inhibitory postsynaptic potentials evoked by 4-aminopyridine in hippocampal neurons in vitro. Brain Res 414:285-293.

Semyanov A, Walker MC, Kullmann DM (2003) GABA uptake regulates cortical excitability via cell type-specific tonic inhibition. Nat Neurosci $6: 484-490$

Semyanov A, Walker MC, Kullmann DM, Silver RA (2004) Tonically active $\mathrm{GABA}_{\mathrm{A}}$ receptors: modulating gain and maintaining the tone. Trends Neurosci 27:262-269.

Shen KZ, Johnson SW (2000) Presynaptic dopamine $\mathrm{D}_{2}$ and muscarine $\mathrm{M}_{3}$ receptors inhibit excitatory and inhibitory transmission to rat subthalamic neurones in vitro. J Physiol (Lond) 525:331-341.

Shen KZ, Johnson SW (2001) Presynaptic GABA $\mathrm{B}_{\mathrm{B}}$ receptors inhibit synaptic inputs to rat subthalamic neurons. Neuroscience 108:431-436.

Smith KJ, Felts PA, John GR (2000) Effects of 4-aminopyridine on demyelinated axons, synapses and muscle tension. Brain 123:171-184.

Smith Y, Charara A, Paquet M, Kieval JZ, Pare JF, Hanson JE, Hubert GW, Kuwajima M, Levey AI (2001) Ionotropic and metabotropic GABA and glutamate receptors in primate basal ganglia. J Chem Neuroanat 22:13-42.

Soares J, Kliem MA, Betarbet R, Greenamyre JT, Yamamoto B, Wichmann T (2004) Role of external pallidal segment in primate parkinsonism: comparison of the effects of 1-methyl-4-phenyl-1,2,3,6-tetrahydropyridineinduced parkinsonism and lesions of the external pallidal segment. J Neurosci 24:6417-6426.
Sohal VS, Huguenard JR (2003) Inhibitory interconnections control burst pattern and emergent network synchrony in reticular thalamus. J Neurosci 23:8978-8988.

Stell BM, Mody I (2002) Receptors with different affinities mediate phasic and tonic $\mathrm{GABA}_{\mathrm{A}}$ conductances in hippocampal neurons. J Neurosci 22:RC223(1-5)

Stell BM, Brickley SG, Tang CY, Farrant M, Mody I (2003) Neuroactive steroids reduce neuronal excitability by selectively enhancing tonic inhibition mediated by $\delta$ subunit-containing $\mathrm{GABA}_{\mathrm{A}}$ receptors. Proc Natl Acad Sci USA 100:14439-14444.

Terman D, Rubin JE, Yew AC, Wilson CJ (2002) Activity patterns in a model for the subthalamopallidal network of the basal ganglia. J Neurosci 22:2963-2976.

Urbain N, Gervasoni D, Souliere F, Lobo L, Rentero N, Windels F, Astier B, Savasta M, Fort P, Renaud B, Luppi PH, Chouvet G (2000) Unrelated course of subthalamic nucleus and globus pallidus neuronal activities across vigilance states in the rat. Eur J Neurosci 12:3361-3374.

Urbain N, Rentero N, Gervasoni D, Renaud B, Chouvet G (2002) The switch of subthalamic neurons from an irregular to a bursting pattern does not solely depend on their GABAergic inputs in the anesthetic-free rat. J Neurosci 22:8665-8675.

Wichmann T, Kliem MA (2004) Neuronal activity in the primate substantia nigra pars reticulata during the performance of simple and memoryguided elbow movements. J Neurophysiol 91:815-827.

Wichmann T, Bergman H, DeLong MR (1994) The primate subthalamic nucleus. I. Functional properties in intact animals. J Neurophysiol 72:494-506.

Wichmann T, Bergman H, Starr PA, Subramanian T, Watts RL, DeLong MR (1999) Comparison of MPTP-induced changes in spontaneous neuronal discharge in the internal pallidal segment and in the substantia nigra pars reticulata in primates. Exp Brain Res 125:397-409.

Wigmore MA, Lacey MG (2000) A Kv3-like persistent, outwardly rectifying, $\mathrm{Cs}^{+}$-permeable, $\mathrm{K}^{+}$current in rat subthalamic nucleus neurones. J Physiol (Lond) 527:493-506.

Wilson CL, Puntis M, Lacey MG (2004) Overwhelmingly asynchronous firing of rat subthalamic nucleus neurones in brain slices provides little evidence for intrinsic interconnectivity. Neuroscience 123:187-200.

Wisden W, Laurie DJ, Monyer H, Seeburg PH (1992) The distribution of 13 $\mathrm{GABA}_{\mathrm{A}}$ receptor subunit mRNAs in the rat brain. I. Telencephalon, diencephalon, mesencephalon. J Neurosci 12:1040-1062.

Wu Y, Wang W, Richerson GB (2003) Vigabatrin induces tonic inhibition via GABA transporter reversal without increasing vesicular GABA release. J Neurophysiol 89:2021-2034.

Yeung JY, Canning KJ, Zhu G, Pennefather P, MacDonald JF, Orser BA (2003) Tonically activated $\mathrm{GABA}_{\mathrm{A}}$ receptors in hippocampal neurons are high-affinity, low-conductance sensors for extracellular GABA. Mol Pharmacol 63:2-8. 